Florida International University FIU Digital Commons

\title{
A model of self-transformative identity development in troubled adolescent youth
}

Richard E. Albrecht

Florida International University

DOI: $10.25148 /$ etd.FI13101567

Follow this and additional works at: https://digitalcommons.fiu.edu/etd

Part of the Psychology Commons

\section{Recommended Citation}

Albrecht, Richard E., "A model of self-transformative identity development in troubled adolescent youth" (2007). FIU Electronic Theses and Dissertations. 1199.

https://digitalcommons.fiu.edu/etd/1199

This work is brought to you for free and open access by the University Graduate School at FIU Digital Commons. It has been accepted for inclusion in FIU Electronic Theses and Dissertations by an authorized administrator of FIU Digital Commons. For more information, please contact dcc@fiu.edu. 
Miami, Florida

\section{A MODEL OF SELF-TRANSFORMATIVE IDENTITY DEVELOPMENT IN TROUBLED ADOLESCENT YOUTH}

A dissertation submitted in partial fulfillment of the

requirements for the degree of

DOCTOR OF PHILOSOPHY

in

PSYCHOLOGY

by

Richard E. Albrecht 
To: Interim Dean Mark Szuchman

College of Arts and Sciences

This dissertation, written by Richard E. Albrecht, and entitled A Model of SelfTransformative Identity Development in Troubled Adolescent Youth, having been approved in respect to style and intellectual content, is referred to you for judgment.

We have read this dissertation and recommend that it be approved.

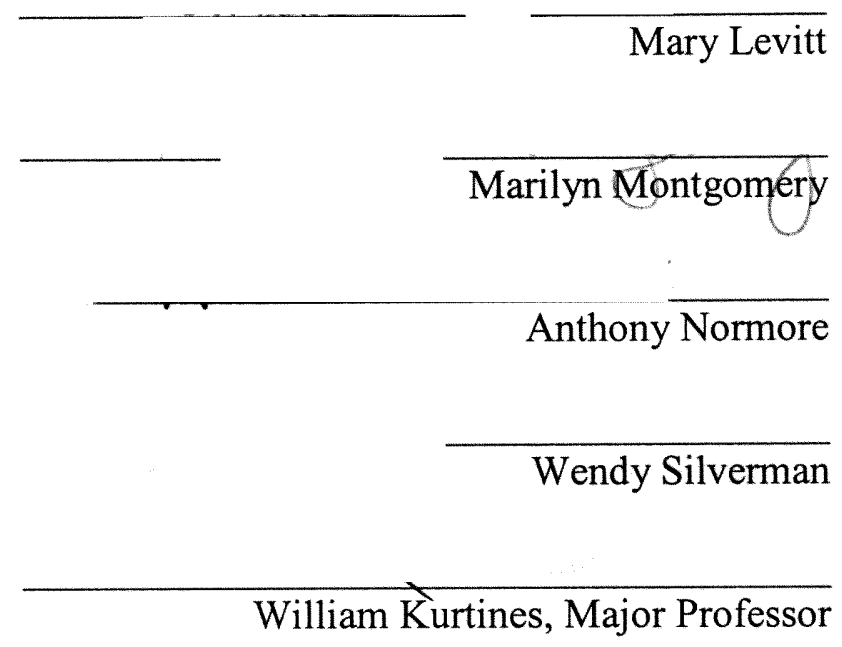

Date of Defense: March 7, 2007

The dissertation of Richard E. Albrecht is approved.

Interim Dean Mark Szuchman

College of Arts and Sciences

- Dean Ğeorge Walker

University Graduate School

Florida International University, 2007 


\section{ACKNOWLEDGMENTS}

Thank you to everyone who has been a part of this process. Dr. Levitt, Dr.

Montgomery, and Dr. Silverman —-thank you for memorable classes and a great deal of guidance over these past years. You helped to mold this lump of clay into something a bit less lumpy. Dr. Normore, thank you for your time, your advice, and your attention to detail. Thanks especially to Dr. Kurtines. It took a lot of talking. Also to Dr. Kurtines and Dr. Jaccard, thank you for your patience, your guidance, and your willingness to laugh with me, not at me. At least, I think you were. And to everyone in the lab who has helped through the past years: Aida, Arlen, Bernice, Kyle, Rachel, Rebecca, and Pi, I appreciated all the great conversations and great food. I am glad that I was able to go through this with all of you. Finally, to my mom, family, and Angel-without your support, there is now way that this could have been done. 


\title{
ABSTRACT OF THE DISSERTATION \\ A MODEL OF SELF-TRANSFORMATIVE IDENTITY \\ DEVELOPMENT IN TROUBLED ADOLESCENT YOUTH \\ by
}

\author{
Richard E. Albrecht
}

Florida International University, 2007

Miami, Florida

Professor William Kurtines, Major Professor

Within the Stage II program evaluation of the Miami Youth Development Project's (YDP) Changing Lives Program (CLP), this study evaluated CLP intervention effectiveness in promoting positive change in emotion-focused identity exploration (i.e. feelings of personal expressiveness; PE) and a "negative" symptom of identity development (i.e. identity distress; ID) as a first step toward the investigation of a selftransformative model of identity development in adolescent youth. Using structural equation modeling techniques, this study found that participation in the CLP is associated with positive changes in PE (path $=.841, \mathrm{p}<.002$ ), but not changes in ID. Increase in ID scores was found to be associated with increases in PE (path $=.229, \mathrm{p}<.002)$, as well. Intervention effects were not moderated by age/stage, gender, or ethnicity, though differences were found in the degree to which participating subgroups (AfricanAmerican/Hispanic, male/female, 14-16 years old/17-19 years old) experience change in $\mathrm{PE}$ and ID. Findings also suggest that moderate levels of ID may not be deleterious to identity exploration and may be associated with active exploration. 


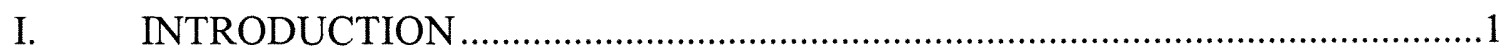

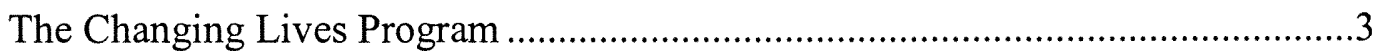

Intervention Theory: A Co-Participatory Transformative Approach .......................4

A Psychosocial Developmental Life Course Approach............................................5

Self-Construction versus Self-Discovery Identity Processes....................................7

A Self-Transformative Model of Identity Development: ......................................13

A Psychosocial Developmental Life Course Approach.........................................13

Contextual Moderators of Self-Change ..............................................................13

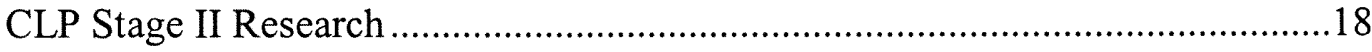

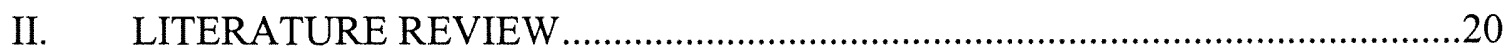

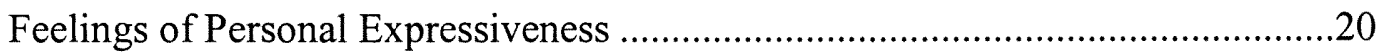

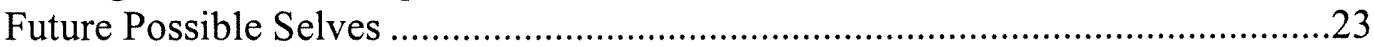

Future Possible Selves Content Categories........................................................26

Content Categories and Developmental Change ...................................................28

Personal Expressiveness and Self Development.....................................................29

Future Possible Selves Content Categories and Feelings of Personal

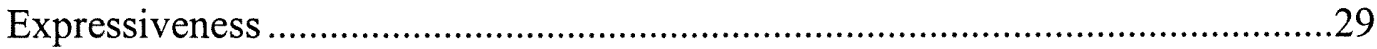

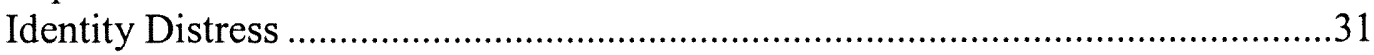

Identity Distress and Emotion-Focused Self-Discovery .........................................32

Positive Development Interventions and "Negative" Developmental Factors .......34

The Current Study ..................................................................................................35

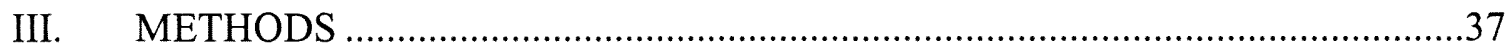

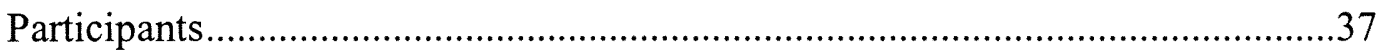

Participant Recruitment and Selection................................................................38

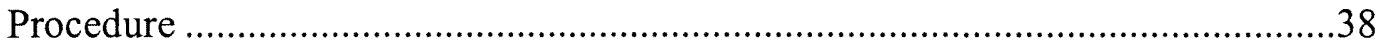

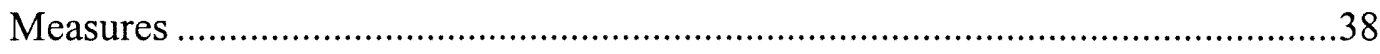

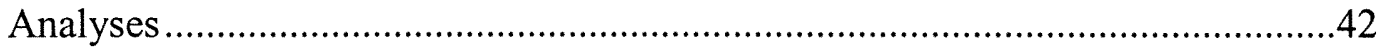

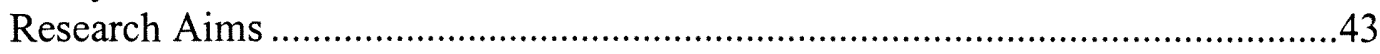

Outcome Research Aim 1 (Efficacy Analyses) ……….....................................44

Outcome Research Aim 2 (Moderation Analyses) ...............................................44

Outcome Research Aim 3 (Directionality of Effects)...........................................45

Exploratory Research Aim 1 (Mediation Analyses) .............................................45

IV. RESULTS …

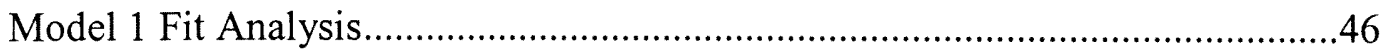

Outcome Research Hypotheses $1.1 \& 1.2$ (Effectiveness and Moderation

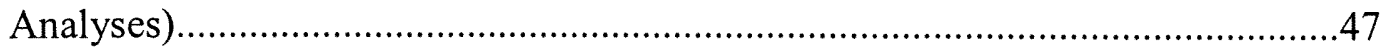

Outcome Research Hypotheses 2.1 (Directionality of Effects) ...........................49

Subgroup Mean Differences: Feelings of Personal Expressiveness ......................49 
Subgroup Mean Differences: Identity Distress ..................................................52

Model 2 Exploratory Mediation Analyses .............................................................54

Subgroup Mean Differences: Future Possible Selves............................................56

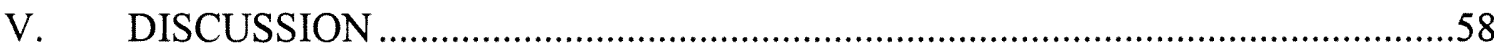

Research Aim 1: Outcome Analyses .................................................................59

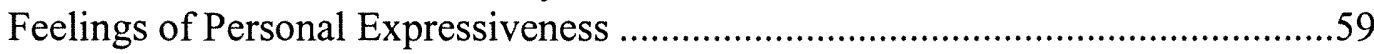

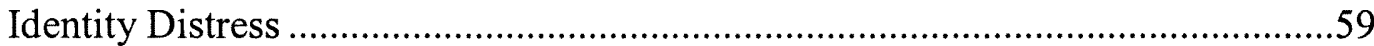

Research Aim 2: Exogenous Moderators of Intervention Effectiveness ...............60

Research Aim 3: Directionality of Effects..........................................................60

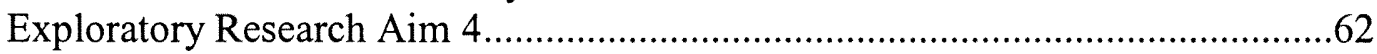

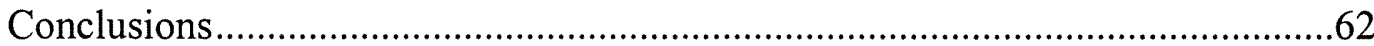

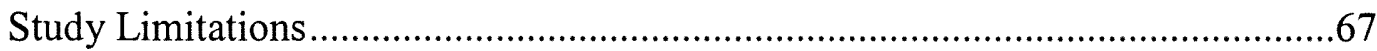

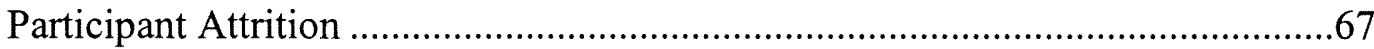

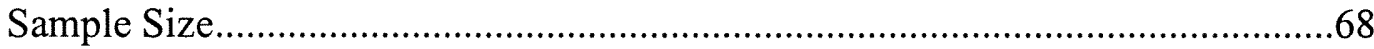

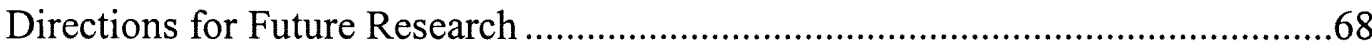

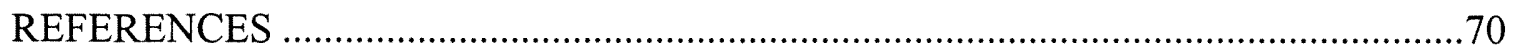

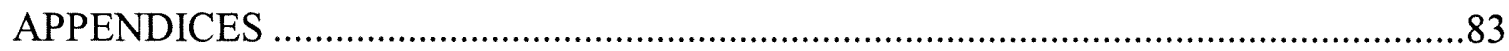

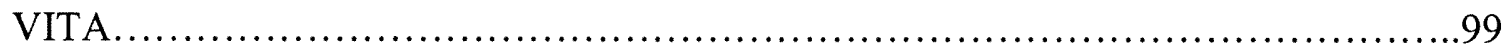




\section{LIST OF TABLES}

TABLE

PAGE

1. Descriptive Statistics for Model 1 Variables........................................50

2. PE Mean Comparisons, Intervention vs. Comparison ............................50

3. Subgroup Mean PE Change Scores............................................51

4. ID Mean Comparisons, Intervention vs. Comparison............................55

5. Subgroup Mean ID Change Scores...........................................53

6. Domains of Most Significant Identity Distress ................................ 54

7. $\mathrm{FPS}_{2}$ Posttest Mean Comparisons, Intervention vs. Comparison ....................57

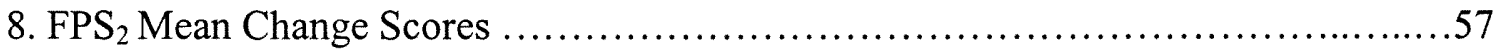




\section{INTRODUCTION}

A Model of Self-Transformative Identity Development in Troubled Adolescent Youth Out of the recognition that interventions need to do more than "treat" problem behaviors and undesirable symptoms (Benson, Scales, Hamilton, \& Sesma, 2006; Csikszentmihalyi, 1998; Kurtines, Ferrer-Wreder, Berman, Cass Lorente, Briones, Montgomery, Albrecht, Garcia, \& Arrufat, in press; Lerner, Fisher, \& Weinberg, 2000), or "prevent" negative developmental outcomes (Damon, 2004; Damon, Menon, \& Bronk, 2003; Lerner, Fisher, \& Weinberg, 2000), recent attention has begun to focus on the development of individuals' strengths and potentials as a means of promoting long term positive development (Schwartz, 2002; Schwartz, Montgomery, \& Kurtines, 2005; Seligman, Steen, Park, \& Peterson, 2005; Waterman, 1993, 2004, 2006). Particular attention has begun to focus on putative intraindividual factors believed to play a role in positive identity development. In this light, a literature has begun to emerge regarding such factors (e.g., Lerner's “The five C's”: Competence, Confidence, Connection, Character, and Caring (Lerner, in press) and Seligman's "character strengths and virtues" (Seligman, Steen, Park, \& Peterson, 2005). However, gaps in the literature remain, specifically with respect to empirically investigated factors believed to play a role in promoting long-term positive development in troubled adolescents (Damon, 2004; Lerner, in press; Lerner, Wertlieb, \& Jacobs, 2003; Seligman et al., 2005). Even less is known with respect to the impact of youth development interventions that seek to promote positive identity development in youth across ethnic and gender lines (Kurtines, 2005; DeCarlo, 2005; Fisher, Hoagwood, Boyce, Duster, Frank, Grisso, Levine, Macklin, Spencer, Takanishi, Trimble, \& Zayas, 2002; Spencer and Markstrom-Adams, 1990). 
Recent attention has begun to focus on the role that cognitive and affective identity exploration have on identity development (Schwartz, Montgomery, \& Kurtines, 2005; Waterman, 1993; Waterman, 2004; Waterman, Schwartz, Goldbacher, Green, Miller, \& Philip, 2003). As individuals evaluate life experiences both in terms of how they think and feel, deliberate engagement in both processes may result in more positive outcomes over time (Schwartz et al., 2005). However, to date, minimal research has been conducted that investigates these processes in adolescents, and specifically troubled adolescents drawn from contexts of ethnic heterogeneity. As positive self development has become broadly conceptualized as the ability of an individual to deliberately structure, and thus acquire, strengths of character from one's life experiences that will facilitate continued positive development through the life course (Dworkin, Reed, \& Hansen, 2003; Scitovsky, 1976; Steen, Kanchorek, \& Peterson, 2003), attention is now turning toward cognitive and affective identity exploration as important factors involved in identity development. Of particular importance to interventions that seek to promote positive identity development, little is known specific to cognitive and affective identity exploration in troubled youth, nor of the feasibility of targeting these factors in intervention to promote increasingly self-directed, deliberate, and positive identity-related choice-making. Given the lack of empirical investigation with respect to these factors in adolescent identity development, this study was conducted to help fill gaps in this literature, as well as the take steps toward the development and evaluation of a selftransformative model of identity development that conceptualizes positive identity development as a largely self-directed process that can be improved through increased cognitive and affective self-understanding. 
The current study was conducted as part of the Miami Youth Development Project's (YDP) Changing Lives Program (CLP) Stage II program evaluation. The CLP is a community-based intervention that seeks to promote positive development in multiethnic, multi-problem youth attending alternative public high schools within the greater Miami, FL area. In line with recommendations for the development of interventions by Rounsaville, Carroll, \& Onken (2001), the on-going CLP Stage II evaluation consists of extension and refinement of previous Stage I pilot/feasibility testing, manual/protocol writing, infrastructure development, and measure development. The Stage II evaluation focuses primarily on psychometric evaluation of measures and short-term controlled outcomes studies ultimately to conduct a Stage III evaluation of long-term change, and possible transportability of the intervention to other settings.

\section{The Changing Lives Program}

The CLP employs group counseling consistent with a transformative model of school counseling described by Keys, Bemak, and Lockhart (1998) that emphasizes the need for interventions to attend to the diverse mental health needs of troubled or at risk youth who attend alternative schools. To help address the problem of limited resources, this model emphasizes group counseling in order to serve more students in an intervention format that is directly relevant to students' needs. Within this format, the CLP groups address a variety of concerns based on participants' needs, dealing with issues such as anger management, troubled families, relationship problems, self-esteem, and alternative lifestyle concerns, depending on students' expressed needs. In addressing these themes, a primary focus of each of these groups is to empower students to take an 
increasingly critical and active role toward evaluating, choosing, and executing the changes they deem necessary to address the problems that they hope to change. Intervention Theory: A Co-Participatory Transformative Approach

The theoretical framework for the CLP intervention (i.e., theory of what to change and how to change it) utilizes a person-centered, co-participatory transformative approach, that draws from both Freire's (1983/1970) transformative pedagogy and multicultural counseling theory (Sue, Carter, Casas, Fouad, Ivey, Jensen et al., 1998; Sue \& Sue, 2003) for its strategies to enhance the critical consciousness of marginalized people (Montgomery, Kurtines, Ferrer-Wreder, Berman, Cass Lorente, Briones, Silverman, \& Eichas, in press). Originally developed for his work with poor rural Brazilians, Freire (1983/1970) described an approach to enhancing the critical consciousness of marginalized people about their exclusion from the mainstream, referred to as transformative pedagogy, a pedagogy of dialogue rather than instruction. This approach emphasized the empowerment of individuals to take an increasingly active role in making their own life choices.

Co-participatory and Transformative Learning. The theoretical framework for the CLP intervention also draws on a Developmental Intervention Science (DIS) perspective, a fusion of developmental science and intervention science. Drawing from developmental science, the CLP seeks to model what changes and how it changes and from intervention science, model what to change and how to change it. In this way, the CLP is specifically committed to the development of both institutional and individual longitudinal change intervention strategies (Kurtines et al., in press). 
Within this DIS framework, this study was focused at the level of individual change strategies, with particular emphasis on strategies for promoting long-term transformational change in self and identity. Positive self-change and long-term transformation have been associated with the opportunity to successfully participate in self-selected and self-directed activities, as these activities are hypothesized to empower youth by strengthening their sense of mastery regarding life choices, intrinsic motivation to achieve life goals, and control and responsibility with respect to life activities (Brandtstadter \& Lerner, 1999; Burger, 1989; Deci, 1992; Herman-Stahl, \& Peterson, 1996; Hunter and Csikszentmihalyi, 2003; Larson, 2000; McWhirter, 1994, 1997, 1998; Peterson \& Reid, 2003; Pittman, 2000; Rich, 2003; Schmidt \& Padilla, 2003; Seligman \& Csikszentmihalyi, 2000; Zimmerman, 1995; Zuckerman, 1979). As positive self development has been associated with the emergence of qualities such as initiation, motivation, self-determination, and interest brought about through active engagement in one's life choices (Deci, 1992; Hunter \& Csikszentmihalyi, 2003; Larson, 2000; Zuckerman, 1979), particular attention is given to promoting increased self-awareness with respect to individuals' strengths, potentials, and qualities as factors that inform lifechoice making. Awareness of personal strengths, potentials, and qualities given the circumstances of one's life is considered a first step toward developing these abilities for future use, specifically with respect to engaging in and positively experiencing situations that have the potential to change one's life for the better. A Psychosocial Developmental Life Course Approach

In seeking to promote positive identity development in adolescents, the CLP draws its developmental framework from both psychosocial developmental theory 
(Erikson, 1968) and life course theory (Elder, 1998), referred to as a psychosocial developmental life course approach. From psychosocial developmental theory, the CLP approach adopts the view of adolescence as the developmental stage at which the individual is first confronted with systematically and seriously addressing the complex and difficult challenges and responsibilities of choosing the goals, roles, and beliefs about the world that give the individual's life direction and purpose, as well as coherence and integration. In short, this is the time at which adolescents begin to specifically address identity-relevant information and answer the question, "Who am I?" (Kurtines, 2005; Erikson, 1968). As such, the period of adolescence is characterized by increased identityrelated exploration, bringing with it increased experimentation, as well as potential risk; increased exploration, however, helps to characterize adolescence as a developmental period when individuals are often more open to the possibility of change, specifically with respect to their goals, roles, beliefs, and feelings (Sherrod \& Brim, 1986).

From life course theory, the CLP intervention adopts an emphasis on how individuals construct their own life course through the choices and actions they make within the constraints and opportunities of the historical, social, and personal contexts in which they live. In addition, as the life course of the individual is worked out over time in terms of established institutional or social pathways, life course turning points may occur-self-directed or not—dramatically impacting the direction of the life course, as well as the individual's understanding and expectations of themselves within their life contexts. The concept of identity derived from psychosocial developmental theory, when integrated with the concept of life transitions and turning points derived from life course theory, provides a link between development, context, and human agency-- i.e., a 
coherent conceptualization of individuals as producers of their own development within the their life contexts (Kurtines, 2005). A psychosocial developmental life course approach thus adapts its view of identity as a "steering mechanism" for life course change and emphasizes the self-directed nature of change in adolescence and adulthood consistent with life course theory (Elder, 1998) and the emerging view of individuals as producers of their development (Brandtstaedter \& Lerner, 1999; Lerner \& BuschRossnagel, 1981). Thus, from a psychosocial developmental life course perspective, the positive development of this "steering mechanism" is of particular importance and has been conceptualized to involve, at least partially, enhanced critical awareness toward one's cognitive and affective experiences of identity-relevant information and contexts. In this context, as part of the on-going evaluation of CLP intervention effectiveness, the focus of this research study was to evaluate the CLP's application of a co-participatory and transformative longitudinal change intervention strategy on promoting selftransformative change, specifically with respect to affective, or emotion-focused, identity exploration.

\section{Self-Construction versus Self-Discovery Identity Processes}

Empirical attention toward investigating and promoting identity exploration and development has most often focused on cognitive processes and skills development in areas such as problem-solving and cognitive decision-making (Enright, Ganiere, Buss, Lapsley, \& Olson, 1983; Ferrer-Wreder, Cass-Lorente, Kurtines, Briones, Bussel, \& Berman, 2002; Markstrom-Adams, Ascione, Braegger, \& Adams,1993; Schwartz, 2002; Schwartz, Montgomery, \& Kurtines, 2005). Known as a self-construction approach, the intervention change strategies used within this approach have focused primarily on 
training individuals to consider potential choices, weigh potential consequences of those choices, and finally, generate any conceivable alternative courses of action. Thus, from a self-construction perspective, identity exploration involves rational, dispassionate consideration of externally presented alternatives (Berman, Schwartz, Kurtines, \& Berman, 2001; Berzonsky, 1990; Grotevant, 1987; Schwartz et al., 2005). A large and growing literature has emerged linking self-construction identity exploration processes (e.g., information processing style and problem-solving approach) to a diversity of identity-related outcomes such as orientation toward education, goal-directedness, as well as one's level of identity commitment (Berzonsky, 1990; Berzonsky \& Kuk, 2000). More recently, a literature has begun to emerge focusing on an alternative to the self-construction perspective on identity development. Known as a self-discovery perspective, this approach adopts an emotion-focused orientation to identity exploration (Schwartz, 2002; Schwartz et al., 2005; Waterman, 1984, 1993, 1995, 2004). Emotionfocused identity exploration is characterized as being "discovery-based," where individuals identify and explore their feelings with respect to specific life activities. Emotion-focused decision-making is therefore largely intuitive, resulting in an affective examination of identity alternatives in terms of how well they resonate with one's "true self' (Schwartz, 2002; Schwartz et al, 2005; Waterman et al, 2003; Waterman, 1984; $1993 ; 1995)$. In this way, identity-relevant information and situations are evaluated by the degree to which they "fit" with the individual, and unlike the dispassionate reasoning, problem solving competence, and alternatives generation of the self-construction approach (Berman et al., 2001; Grotevant, 1987), the self-discovery approach is rooted in Maslow's (1968) theory of self-actualization and in Csikszentmihalyi's (1990a) theory of 
flow, where particular emphasis is placed on intra-individual subjective experience (Schwartz et al., 2005).

The subjective experience of self-discovery is conceptualized to consist of three levels of affective processing, with successively more advanced levels incorporating and integrating into previous ones. In order of increasing integration, the three levels of selfdiscovery are flow, personal expressiveness, and self-actualization (Schwartz, 2002; Schwartz et al, 2005; Schwartz, 2006; Waterman, 1990). The experience of flow is a subjectively positive state produced by participation in activities in which the challenge at hand is balanced by the skills one brings to it. The experience is flow results in an unconstrained sense of time and intense engagement in the activity or pursuit of the goal (Csikszentmihalyi, 1990a; 1990b; Waterman, Schwartz, Goldbacher, Green, Miller, \& Philip, 2003). Feelings of personal expressiveness is the deep satisfaction that accompanies engagement in activities or goals that capitalize on one's unique strengths or potentials. These feelings often result from incorporating flow-producing activities, goals, and ideals into one's sense of identity giving the sense that this is what one was meant to do. Self-actualization refers to fulfilling one's potentials and living up to one's ideals on a consistent basis (Maslow, 1968).

As previously noted, the main trends in the literature on interventions targeting identity development have tended to use cognitive strategies for promoting (cognitive) self-construction exploration processes (Archer, 1994; Enright et al., 1983; FerrerWreder, et al, 2002; Markstrom-Adams et al., 1993). The emergence of an intervention approach that adopts an emotion-focused orientation to identity exploration (Schwartz, 
2002; Schwartz et al., 2005) has resulted in a small but growing literature investigating the role of self-discovery exploration processes on identity development.

Specifically, recent research has begun to address the question of the relative contribution of each type of process (i.e. self-construction and self-discovery) to identity development. Although preliminary, the initial findings from this research indicate that optimally, interventions that seek to promote positive identity development should target both self-construction and self-discovery identity exploration processes, as individuals evaluate life activities from both perspectives (Schwartz, 2002; Schwartz et al., 2005; Soenens, Berzonsky, Vansteenkiste, Beyers, \& Goosens, 2005; Waterman, 2004).

Schwartz et al. (2005), for example, conducted an exploratory investigation to study the effect that the use of self-construction and self-discovery intervention strategies to promote self-change in a multiethnic sample of 90 emerging adult university students. The study used a quasi-experimental design to evaluate the relative impact of the construction and discovery intervention strategies on exploration processes. A nonintervention comparison control condition (CC) was also included. For all three conditions, pretest assessments were conducted at the beginning of the semester and posttest assessments conducted at the end of the semester (approximately a 10-week interval). Posttest data were collected from control condition participants and from participants in the active conditions who completed the intervention.

The active intervention conditions in the Schwartz et al. (2005) study consisted of the following intervention activities: In the construction-focused condition, each participant brought one important, identity-related life choice or dilemma for group discussion and problem-solving. The participant who had brought the choice to the 
session was encouraged to participate in transformative activities by trying out the alternatives that had been identified by the group; in the emotion-focused condition, each participant brought to their group three goal strivings for group discussion which was then used in a five step intervention process that drew on the work of Greenberg, Rice, and Elliott (1993) and Waterman (1990).

First, the goal striving was broken down into component activities (e.g., going to law school = reading, studying, memorizing). Second, the participant was asked to associate each component activity with feelings and feeling words (e.g., angry, stressed, fearful), using the experiential focusing technique outlined by Greenberg et al. (1993), discussed later in this paper. Third, the group facilitator introduced the concept of flow. Fourth, the participant was instructed to create a list of activities that he or she associated with feelings of flow, and the facilitator wrote these on the blackboard as the participant enumerated them. Finally, the group was asked to construct goal strivings using the flow activities and to integrate creatively these "flow goals" into the participants' existing personal strivings. The participant was then asked to reflect on these integrated goal strivings.

Consistent with their outcome expectations, Schwartz et al. (2005) reported support for the impact of cognitive strategies on (cognitive) self-construction exploration processes and of emotionally focused strategies on (emotion-focused) self-discovery exploration processes. The study specifically found that participants in the cognitive condition significantly increased their ability to generate multiple alternatives and to consider positive aspects of lowly regarded options when faced with an important life decision; these participants showed no statistically significant change in self-discovery 
processes. Conversely, participants in the self-discovery condition experienced increases in feelings of personal expressiveness while pursuing their goal strivings and showed no statistically significant change in cognitive processes. All study participants offered positive qualitative feedback with respect to their condition's usefulness in helping them to achieve their self-identified change goals.

These findings were taken to suggest that self-construction and self-discovery processes are distinct from one another, but are part of, and therefore, necessary for, optimal identity development and intervention promoting the same (Schwartz et al., 2005). In line with these findings, more recent research suggests that these processes may be experienced concurrently, affecting each other as an individual cycles between thinking and feeling when presented with identity-relevant information (Soenens et al., 2005).

This emerging literature provided the springboard for this study. As discussed below, a long term goal of the YDP and the CLP in particular, is to evaluate a selftransformative model of identity development, particularly as it applies to promoting positive identity development across the lifespan. In the context of the existing and emerging research literatures, however, the goals of this current study were more narrowly delimited in scope, and were designed to fill in some crucial gaps in the newly emerging literature on the self-discovery approach. In light of the more extensive literature with respect to cognitive-oriented self-construction intervention approaches, a primary focus of this research study was to investigate whether the CLP's coparticipatory transformative approach promotes positive change in emotion-focused selfdiscovery processes. In the context of the relative dearth of literature on promoting self- 
discovery, particularly in troubled adolescent youth, this was considered an essential first step for Stage II study prior to undertaking a full scale randomized trial comparing the two approaches.

A Self-Transformative Model of Identity Development:

A Psychosocial Developmental Life Course Approach

Drawing on the psychosocial developmental life course approach outlined above, the literature on self-discovery (Epstein, 1991; Schwartz, 2002; Schwartz, Kurtines, \& Montgomery, 2005; Soenens et al., 2005; Waterman, 1993; Waterman, et al, 2004), and the pioneering research of Schwartz and his colleagues (Schwartz et al., 2005), a SelfTransformative Model of Identity Development is proposed that is designed to guide CLP intervention work with adolescents. As this model draws its basic features from a psychosocial developmental life course approach, this model of identity self-development is intended to apply across the lifespan (or at least from adolescence through adulthood). However, because self-discovery identity processes have, to this point, been understudied relative to self-construction processes, particularly in adolescent youth, self-construction processes were not evaluated in the current trial. Instead, focus was given to selfdiscovery and examination of various factors hypothesized to moderate self-discovery identity exploration and CLP intervention outcomes.

\section{Contextual Moderators of Self-Change}

Findings from previous research within the CLP regarding the role exogenous contextual moderators such as gender and ethnicity have on intervention outcomes are mixed. The association between participation in CLP and positive change in identity development as assessed by the YDP Life Course Interview, for example, was not found 
to be significantly moderated by gender and ethnicity (Lewis Arango, Kurtines, Montgomery, \& Ritchie, in press). However, the association between participation in CLP and positive change in future possible selves as assessed by a qualitative extension of the Possible Selves Questionnaire (PSQ-QE), was reported to be significantly moderated by gender and ethnicity and also by a gender by ethnicity interaction (Kortsch, Kurtines, \& Montgomery, in press). Though previous research outside CLP has suggested that the process of identity development is generally similar for males and females (Kroger, 1997; Waterman, 1993), findings within this literature, particularly with respect to non-majority ethnic samples, are mixed (Soenens et al., 2005; Schwartz \& Montgomery, 2002; Sorrel \& Montgomery, 2001; Cole, 1998). Given these mixed findings and due to its use of a sample drawn from contexts of multi-ethnic heterogeneity, CLP research remains focused on investigating potential moderating effects these factors may have on intervention outcomes. This focus also extends to any putative factors of positive identity development, including "negative" factors believed to potentially hinder positive identity development.

Little is understood regarding "negative" factors (identity distress, identity diffusion, identity role confusion, etc.) on positive identity development and intervention outcome with troubled adolescents, as questions remain whether "negative" factors may be involved in normative developmental processes, or as relevant factors in positive development intervention. This is of particular relevance to interventions seeking to promote positive identity development in troubled youth, as these youth are known to often experience difficulties in many life domains (e.g., school, community, and home) (Duchnowski, Kutash, \& Friedman, 2002); as a consequence, the issue of whether 
promoting positive identity development is associated with beneficial change in the experience of negative factors in these life domains is an important one.

Evidence has begun to build that positive development interventions, in general, do have success in decreasing negative symptoms while increasing other factors associated with positive development (Garcia, 2005). To date, however, no such research has been conducted within the CLP. The lack of empirical evidence regarding this issue, however, takes on additional significance in view of the findings of research using data drawn from the same general population of the CLP. This research identified identity distress as one type of "negative" factor shown to be experienced by up to one-third of the alternative high school population from which the CLP sample is drawn (Hernandez, Montgomery, \& Kurtines, 2006). Although theory might suggest that a reduction in identity distress is associated with more positive identity development, there is currently little research to support this. An alternative hypothesis, for instance, might consider positive identity development to be associated with increased identity distress, as the challenge of leaving a relatively secure developmental status at one level and moving in the direction of personal growth in new areas may be a potentially stressful process. Thus, the relationship between identity distress and positive identity development remains an empirical question. In this context, one of the research aims of this study was to investigate the directionality of the hypothesized link between positive identity development (operationalized as feelings of personal expressiveness; see below) and identity distress. 
Figure 1 is a representation of a general self-transformative model of identity development. In it, one's sense of self is hypothesized to be the direct result of both selfdiscovery and self-construction processes, as well as contextual factors like those described previously (i.e. age, gender, ethnicity, identity distress, etc.) that may moderate identity processes. Contextual factors may have positive or negative effects on one's sense of self, and may also be associated with changes in self-discovery and selfconstruction processes.

In Figure 1, rectangles represent hypothesized variables. Arrows (a,b,c,d) represent hypothesized causal paths. Predicted directionality of change for all paths is represented by a " + " or " - ." This model illustrates historical, social, and/or personal contextual opportunities/constraints to have a direct association with one's sense of self. This relationship is also hypothesized to be partially or fully mediated by selfconstruction and/or self-discovery identity processes. Both self-construction and self-

Figure 1: Self-Transformative Model of Identity Development

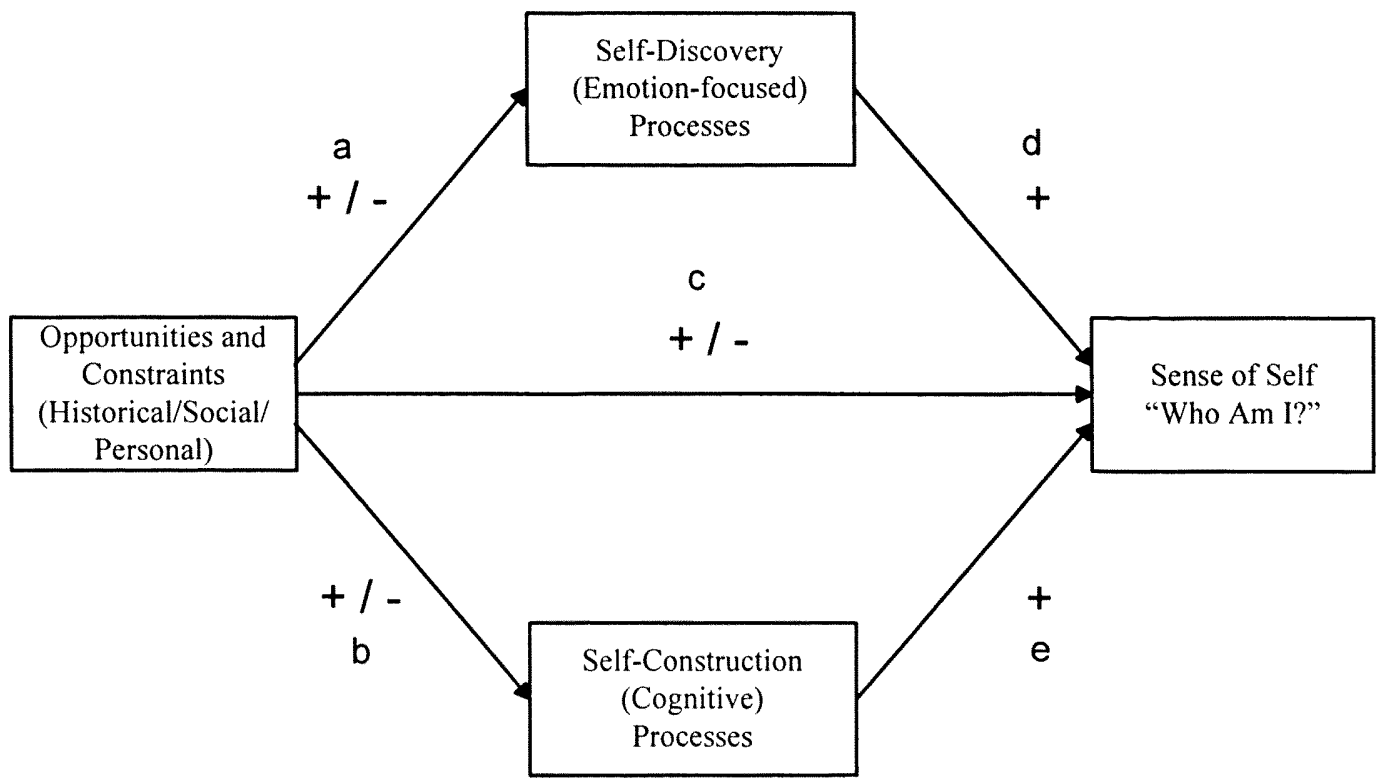


discovery are considered to have positive effects on identity development, while contextual factors may have variable associations.

Figure 2 is a more specific representation of the model analyzed in this study.

Primary analyses were conducted to evaluate CLP intervention effectiveness in promoting positive change in feelings of personal expressiveness (path a) and a decrease in expressed levels of identity distress (path b). These intervention effects were hypothesized to be moderated by stage/age, gender and ethnicity (paths a and b).

Figure 2: Investigated Outcome Model

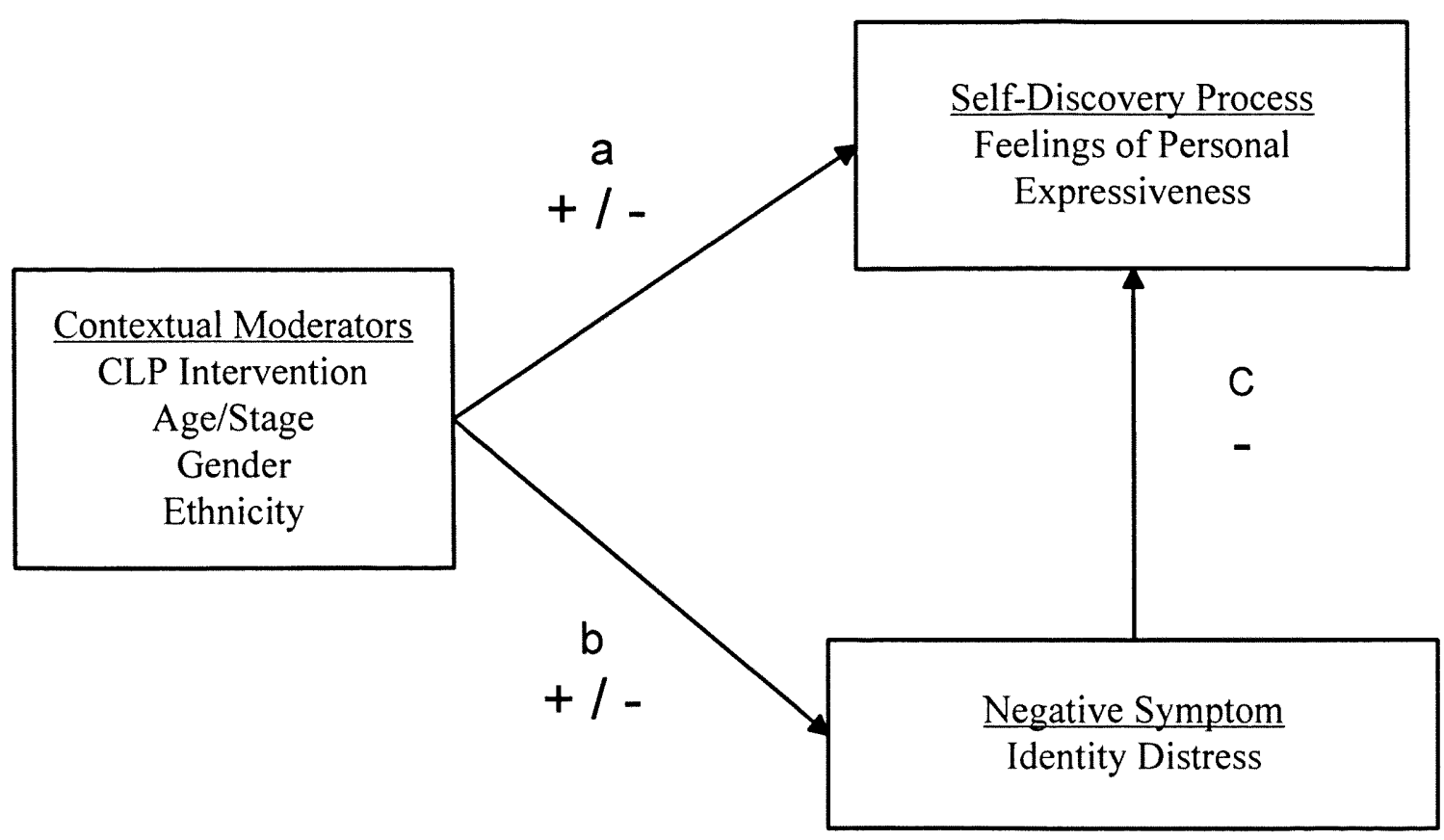

As literature is mixed with respect to gender and ethnicity-related differences in identity development, moderation by stage/age, gender, and ethnicity is hypothesized to be potentially associated with increases or decreases in identity exploration and identity 
distress. Increased levels of identity distress are believed to be related to decreased experience of emotion-focused self-discovery (path c).

In addition to analyses conducted using the model represented in Figure 2, secondary exploratory analyses were also conducted including a measure of self to this model, representing a basic version of the self-transformative model of identity development illustrated in Figure 1 above.

\section{CLP Stage II Research}

This study was conducted as part of the early Stage II evaluation of the CLP coparticipatory, transformative intervention approach on self-discovery identity exploration in troubled adolescent youth. Empirical attention was also focused on examination of putative exogenous contextual moderators on self-discovery identity exploration processes (i.e. age/stage, gender, and ethnicity). In addition, analyses included an examination of identity distress as a potential negative symptom of identity development. This study had three main research aims and one exploratory research aim to identify potential avenues for continued investigation.

The first outcome aim of this study was to investigate CLP intervention effectiveness in promoting positive change in self-discovery processes (i.e. feelings of personal expressiveness) and an endogenous contextual factor believed to negatively affect identity development (i.e. identity distress). The second research aim of this study was to investigate a hypothesized link between feelings of personal expressiveness and identity distress where a decrease in identity distress has been theoretically associated with positive change in feelings of personal expressiveness. The third research aim was to investigate the directionality of change in feelings of personal expressiveness and identity 
distress following participation in the CLP intervention. In hopes of taking the first steps toward evaluation of a full self-transformative model of identity development, the fourth research aim was to conduct an exploratory investigation of feelings of personal expressiveness as a potential mediator of an individual's sense of self (i.e. future possible self). 


\section{LITERATURE REVIEW}

\section{Feelings of Personal Expressiveness}

A considerable literature has developed focusing on self-discovery-oriented positive self-development, with much of this literature asserting that effective selfdevelopment, as well as intervention intent on promoting positive self development, must attend specifically to enhancing individuals' personal strengths and creative potentials (e.g., Berlyne's “exploratory drive," Horney's "self-realization," Rogers' and Maslow's "self-actualization," Csikszentmihalyi’s “flow," Waterman's "feelings of personal expressiveness" (Yalom, 1995)).

Particularly useful with respect to identity development, discovery and understanding of one's potentials, strengths, and abilities is believed to be directly associated with who one chooses to become, as these aspects of self can be more effectively incorporated into means of achieving one's life goals (Schwartz, Montgomery, \& Kurtines, 2005; Waterman, 1993; Waterman, 2004; Waterman, Schwartz, Goldbacher, Green, Miller, \& Philip, 2003). As mentioned above, feelings of personal expressiveness have been described as positive, subjective state characterized by the deep satisfaction that accompanies engagement in activities or goals that utilize one's unique potentials and that are hypothesized to represent one's basic purpose in living (Waterman, 1993). These feelings result from incorporating activities, goals, and ideals into one's sense of identity and reflect one's core sense of being (Waterman et al, 2003). Specifically, while engaging in personally expressive activities, individuals experience 1) unusually intense involvement, 2) a special fit or meshing with the activities, 3) feelings of being intensely alive, 4) feelings of completeness or fulfillment, 5) an impression that 
this is what one was meant to do, and 6) feelings of who one really is (Waterman, 2005; Waterman et al., 2003).

Research suggests that individuals who more frequently engage in personally expressive activities exhibit more positive life outcomes than those who engage in activities that provide mostly extrinsic reward or are purely of hedonic enjoyment (Csikszentmihalyi, 1975, 1988, 1990b; Waterman, 1993, 2004), in part because individuals who actively engage in personally expressive activities demonstrate an ability to remain intrinsically motivated toward accomplishing life tasks (Waterman, 2006). Importantly, these individuals also report greater perceived competence, and higher scores for self-realization values, and importance (Waterman, 2005). Though individuals vary in terms of their involvement in personally expressive activities, for purposes of illustration, individuals may fall into one of two groups - those who engage in emotionfocused decision-making and those who do not (Waterman, 2004). For the personally expressive group, a set of personal interests, potentials, and abilities help to guide choicemaking, particularly with respect to identity-relevant decisions, as these interests, potentials, and abilities often elicit deep feelings of enjoyment that help to inform their choices and also cause the individual to gravitate toward personally expressive activities in the future (Waterman, 2004). The second group, however, gravitates toward activities that are not personally expressive, but that instead provide more immediate, predominantly hedonic pleasure or enjoyment and/or extrinsic rewards. The distinction between these two groups suggests that while pleasure is often associated with both personally expressive and hedonic experiences, personally expressive activities are more "fit" with the individual and tied to a deeper sense of satisfaction that is more intrinsic 
and more likely to promote further engagement and positive development into the future (Csikszentmihalyi, 1990a; Waterman, 2004).

As individuals exist and operate within historical, social, and personal contexts the experience of personally expressive activities is plausibly enhanced or decreased by some of these factors, as well (Obler \& Fein, 1988; Waterman, 2004). However, Waterman (2004) points out that despite possible limitations on one's ability to engage in some life activities, the experience and development of one's interests, potentials, and abilities can take many different directions, especially as awareness of one's interests, strengths, and potentials develops. This means that for individuals who have yet to identify personally expressive activities in their life, broad self-exploration of one's potential interests holds the greatest promise for discovering previously hidden potentials and strengths (Waterman, 2004). Furthermore, knowledge of one's strengths and potentials may allow the individual to identify, seek out, and adapt more readily to new challenges should constraints preclude participation in some desired activities. Therefore, understanding one's own interests, potentials, and abilities given the opportunities and limitations of historical, social, and/or personal contexts is likely to expand the possible directions one's life can take and may help lead to a more satisfying, sustainable life course.

Recalling that positive affective experience of identity-relevant activities is believed to be associated with increases in associated self-discovery (Montgomery et al., in press), the developmental implications of Waterman's claims, if true, are considerable, particularly so for those experiencing difficulties developing a sense of self that allows for more effective navigation of life's challenges. That is, a dispositional integration of 
activities or goals that are personally expressive into one's on-going life course has the potential to make a substantial positive contribution to one's basic sense of purpose in living and one's connectedness to the tasks of living. Therefore, as an individual continues to participate in emotion-focused self-discovery and becomes increasingly aware of their own strengths and potentials, an individual's ability to conceptualize a temporal extension of their feelings toward future life goals and the activities necessary to achieve them may be linked to one's conceptualization of who they can become in the future. In this way, the more closely "fit" an individual feels toward achieving their life goals, the greater the potential for success.

Operating within the CLP Stage I evaluation, Albrecht (2005a) conducted a preliminary investigation of feelings of personal expressiveness (PE) in the multi-ethnic sample of adolescent youth served by CLP. This study provided evidence for a conceptual link between feelings of personal expressiveness and identity development in troubled adolescents and that participation in the CLP intervention was associated with a slight increase in PE scores from pre- to posttest relative to comparisons. These results provided support that self-discovery identity exploration can be increased through selftransformative intervention strategies, in line with previous CLP research that found these strategies to be effective in promoting a more positive sense who one hopes to become in the future.

\section{Future Possible Selves}

Examining approximately the same sample as that used in Albrecht (2005a), Kortsch (2003) found that the intervention strategies used by the CLP demonstrated effectiveness with respect to promoting a more positive sense of future self (i.e. future 
possible self; Oyserman, 1987), one aspect of the development of an overall positive, increasingly consolidated sense of self. One's future possible self is the conceptualization of self an individual believes they could become, hopes to become, or hopes to avoid becoming, that has been found to be an important contributor to identity formation (Dunkel, 2000). Future possible selves represent one aspect of the ability to conceptualize the self in the future based on one's past and present, given historical, social, and personal opportunities and constraints (Dunkel \& Kerpelman, 2006; Markus \& Nurius, 1986). As such, one's conceptualization of "who one is" is believed to strongly influence one's expectations and beliefs about the directions one's life can take, as this conceptualization draws on one's past, one's present, and one's perceived potential futures. Indeed, research has demonstrated a link between possible selves and an individual's ability to orient towards the future in a personally meaningful way (Oyserman \& Markus, 1990a, 1990b; Oyserman \& Fryberg, 2006). In terms of developing a personally meaningful orientation toward the future, future possible selves help to define an individual's self-perceptions given past, present, and possible future contextual opportunities and constraints.

This provides a link between the individual and their context and also may serve to help individuals begin to conceive of potential courses of action to achieve this conceptualization of the self. Perhaps most important to self-directed development, when answering "who I want to become," important criteria may include a personal striving that is either goal- or trait-oriented, or defined by successful avoidance of the same (e.g., achieve a career or family objective versus changing a personal trait or quality). In terms of personal traits, improved self-understanding with respect to one's abilities and one's 
perceived limitations provides an opportunity for positive change as the potential outcomes of employing these traits toward achieving life goals gains focus.

As part of the CLP Stage I evaluation, Kortsch (2003) investigated intervention participants' qualitative expressions of their future possible selves, including what achievement of that self would mean and how significant that achievement would be. Using the Possible Selves Questionnaire-Qualitative Extension (PSQ-QE) that builds on the Possible Selves Questionnaire (PSQ; Oyserman, 1987), responses to the PSQ-QE were used as an index of one component of the individual's overall sense of identity, (i.e., the future self as one sees it). Participants' qualitative responses were coded using Relational Data Analysis (RDA; Kurtines, Montgomery, Lewis Arango, \& Kortsch, 2005). Relational Data Analysis (RDA) is a multidimensional, multi-phasic framework for unifying the use of data analytic strategies across both dimensions of analysis (quantitative/qualitative, causal/structural, etc.) and phases of analyses (conceptual, theoretical, and research analyses). Appendix A provides a more detailed description of RDA.

The conceptual and theoretical coding phases of RDA yielded findings with respect to participants' future possible self orientations. Specifically, responses were found to fit into three general types: Self-Oriented; Other-Oriented; or Other/Self. That is, participants' responses focused primarily on themselves, on others, or on themselves and others. Within the Self- and Other-Oriented categories, three main subgroups of interest were found: Self-Satisfying; Self-Actualizing, and; Altruistic. For individuals in these subgroups, their most hoped for future possible self was found to express qualities that indicated either pure focus on one's own desires usually of a hedonic nature (Self- 
Satisfying), focus on the achievement of one's potentials (Self-Actualizing), or focus on helping others with no mention of self-satisfaction (Altruistic). Kortsch (2003) found that with respect to participation in the CLP intervention, the basic pattern of qualitative change for participants' responses on the PSQ-QE after one year of intervention participation tended to be positive, significant, and in the hypothesized direction (from self-satisfying to more self-actualizing or altruistic in orientation).

\section{Future Possible Selves Content Categories}

The category descriptions for the three main subgroups are below:

Self-Satisfying. The unique properties of the Self-Satisfying sub-category was that it did not include any reference to the meaning and significance of future possible selves to others but that it did include explicit references to the meaning and significance of future possible selves to the self. Responses in this category included references to striving for individual or personal pleasure or satisfaction (for the self) that tended to be present-oriented and described in terms that could be characterized as involving extrinsic rewards, hedonic enjoyment, materialistic satisfaction, or self-gratifying in orientation (or avoiding the loss of the same). Because all the responses that were included in the SelfSatisfying category also meet the criterion for the Self-Oriented, the theoretical coders identified Self-Satisfying as a sub-category of the Self-Oriented Category.

Self-Actualizing. The unique properties of the Self-Actualizing sub-category was that it did not include any reference to the meaning and significance of future possible selves to others; that it did include explicit references to the meaning and significance of future possible selves to the self; and that these included references to striving for individual or personal pleasure or satisfaction (for the self) that tended to be future- 
oriented and described in terms that could be characterized as involving striving for the realization of one's potential (i.e., self-realization). Thus, some respondents who described the meaning and significance of their most important future possible self in terms that could be characterized as self-satisfying also included additional content making explicit reference to ways of obtaining gratification, personal pleasure, or satisfaction (for the self) that could be further characterized as self-actualizing and/or oriented toward long-term future goals (or avoiding the loss of the same or both). Thus, response data classified under the Self-Actualizing also shared at least one of two (or both) additional properties that they did not share with the Self-Satisfying category.

First, these responses either reported a "temporal" extension of self-satisfaction that described self-satisfaction beyond the pleasures or reward of the moment and the here-and-now that includes the long-term satisfaction of the self using descriptive words and phrases such as, "always wanted to be," "this is my dream," "what I am meant to be" "who I am," "it's part of my tradition," "my vision," "my life goal." etc. Second, these responses reported an "actualizing" extension of self-satisfaction that described selfsatisfaction in ways that focused on what was being actualized rather than the pleasure or reward to be obtained. The concept of "self" actualization implies a level of "bringing into being," or self-realization of qualities unique to the self, such as special talents, competencies, personal qualities, etc.

Altruistic. The unique property of the Altruistic category was that it included descriptions of the meaning and significance of future possible selves that were characterized in terms of gain, satisfaction, or benefit of the individual's future possible self to others (or avoiding the loss of the same) and included no reference to its meaning 
and significance to self. Unlike the Self-Satisfying and Self-Actualizing groups, the Altruistic group was found to be entirely Other-oriented.

\section{Content Categories and Developmental Change}

As described in detail in Kortsch and Kurtines (2005), the structural organization of the relationships between the three qualitatively different categories (Self, Other, Other-Self) was tentatively identified as flat, or non-hierarchical. However, the structural organization of the properties within each of the three main sub-categories was identified in terms of the unique structural arrangement of the properties and/or associated subcategories within each category, to have developmental directionality, or hierarchy, based on current conceptions of self development during adolescence.

As adolescence is considered a developmental period characterized by a shift from childhood egocentricism to the more socio-centric orientation of adulthood, as well as the formation and development of a more advanced "self-structure," the categorical structures described in Kortsch (2003) and Kortsch and Kurtines (2005) mirror theoretical developmental expectations. The theoretical coders reached a consensus that the Self-Satisfying group is the least developmentally advanced category, as a primary characteristic of this group remains largely egocentric. The remaining Self-Actualizing and Altruistic groups, and the mixed subgroups, as they suggest movement toward an increasingly socio-centric orientation, were considered to be more developmentally advanced. Meaningful theoretical differences, and thus developmental hierarchy, could not be discerned between the Self-Actualizing and Altruistic groups. As such, to focus more clearly on directionality of change, the Self-Actualizing and Altruistic categories were both considered more developmentally advanced than the egocentric Self-Satisfying 
group, but not more developmentally advanced relative to each other in any way theoretically meaningful from the Psychosocial Developmental Life Course approach used in this study. From such perspective, a change from a purely Self-Satisfying category to either a Self-Actualizing or an Altruistic category (or mixed combinations of these categories) was considered an indicator of positive developmental change. Personal Expressiveness and Self Development

As adolescence is considered a time when an individuals' sense of identity develops into an increasingly self-directed, coherent, and dynamic organization of the individual's drives, abilities, beliefs, and personal history (Kortsch and Kurtines, 2005) qualitative distinctions between the future possible selves content categories (i.e., SelfSatisfying, Self-Actualizing, Altruistic) may indicate that one's conceptualization of a hoped for future possible self is at least partially defined by the degree to which it is personally expressive. In terms of developing a positive sense of identity, personally expressive individuals may conceptualize their future in terms of fulfillment of known interests, strengths, and potentials thus increasing the potential for continued positive development into the future, whereas less personally expressive individuals may conceptualize their future self in terms of hedonic pleasure or extrinsic reward, potentially limiting future growth.

Future Possible Selves Content Categories and Feelings of Personal Expressiveness

Examining qualitative differences between the three main possible self subgroups (Self-Satisfying, Self-actualizing, Altruistic), self-satisfying possible selves include no reference to feeling a personal "fit" with their hoped for self and instead make explicit references to striving for individual or personal pleasure/satisfaction, materialistic gain, 
extrinsic reward, and/or self-gratification. Because these possible selves lack a specific reference to a striving beyond gratification or direct reinforcement and make no reference to a defined purpose in living, and as their focus is self-satisfaction that does not go beyond immediate, hedonic reward, individuals with this hoped for future self might be presumed to score low on feelings of personal expressiveness while engaging in activities necessary to achieve that goal.

Self-actualizing possible selves, however, include references to striving for individual or personal pleasure or satisfaction (for the self) that tended to be futureoriented and described in terms that could be characterized as involving striving for the realization of one's potential. These responses report a "temporal" extension of selfsatisfaction that suggests a more long-term orientation to who they hope to become. These responses often include descriptive words and phrases such as, "always wanted to be," "this is my dream," "what I am meant to be" "who I am," "it's part of my tradition," "my vision," "my life goal." etc. Such responses may potentially be considered more personally expressive than pure Self-Satisfiers, as the focus on the self is described in terms of respondents' personal connection to their hoped for self as an indicator of "being actualized" as a subjectively "better" self, one that is largely removed from considerations of immediate, extrinsic pleasure or reward (Kortsch and Kurtines, 2005).

Finally, the Altruistic possible selves category is characterized in terms of gain, satisfaction, or benefit of the individual's future possible self to others (or avoiding the loss of the same) without specific reference to its meaning and significance to self. These responses consist of hoped for future selves that give little verbal indication regarding the degree to which these selves and associated activities are personally expressive. 
However, as research suggests that personally expressive individuals demonstrate high levels of intrinsic motivation, a sense of completeness/fulfillment, increased competence, and an impression that this is what they were "meant to do" (Waterman, 2005; Waterman et al., 2003), the focus on service to others strongly suggests that an orientation toward helping others is likely associated with a high degree of personal expressiveness.

As research has demonstrated a link between possible selves and severity of delinquent behavior, as well as psychosocial maturity (Oyserman and Markus, 1990a, 1990b; Oyserman \& Fryberg, 2006), the role negative factors, such as identity distress mentioned previously, play in the development of one's sense of self are also of interest. As identity distress has also been associated with symptoms of poor psychological adjustment in adolescent youth (e.g., internalizing and externalizing behaviors; Hernandez, Montgomery, \& Kurtines, 2006), identity distress and future possible selves may be plausibly linked.

\section{Identity Distress}

Originally developed for the diagnosis of Identity Disorder, a diagnostic category that's essential feature was severe subjective distress regarding the inability to integrate aspects of the self into a relatively coherent and acceptable sense of self (Diagnostic and Statistical Manual of Mental Disorders (3rd ed., rev. [DSM-III-R], American Psychiatric Association, 1987), the Identity Distress Scale (IDS; Berman, Montgomery, \& Kurtines, 2006) has been shown to be a valid tool toward understanding the degree to which individuals experience identity-related distress (Hernandez et al., 2006). Although Identity Disorder has been removed from the DSM and no longer remains a DSM diagnostic category, the IDS continues to be useful to understand individuals' subjective 
experience regarding the degree to which adolescents find their own self-development difficult and upsetting (Berman et al., 2004; Hernandez et al., 2006).

Previous research within the Youth Development Project (i.e., Hernandez et al., 2006) has shown that approximately one third of adolescents studied from the same general population used by the CLP report significant levels of identity distress relative to a sample of university students; that is, these individuals reported moderate, severe, or very severe upset, distress, and/or worry with regard to a number of identity relevant domains, such as long-term goals, career choices, friendships, sexual orientation and behavior, religion, values and beliefs, and group loyalties. As future possible selves and identity distress have been linked to maladaptive behaviors that bring with them further disruption, elevated levels of identity distress may function to constrain identity development processes (e.g., emotion-focused identity exploration and cognitive selfconstruction) and the development of a positive sense of self (e.g., future possible self).

\section{Identity Distress and Emotion-Focused Self-Discovery}

The potential disruption caused by identity-related distress, and any resulting internalizing/externalizing behaviors, may be associated with a decreased ability to navigate effectively important developmental contexts. Particularly for adolescents, contexts such as school, one's community, peer groups, family, and work, amongst others (Duchnowski et al., 2002), could be seriously disrupted, as the individual's involvement within these contexts is more frequently experienced as distressing, difficult, and something to "survive," or "cope with." Additionally, associated internalizing and/or externalizing behaviors may publicly label and stigmatize the individual as "delinquent," precluding more positive participation in developmentally important activities (Shih, 
2004), such as education and occupation, either through expulsion from school or work, incarceration, or escalating maladaptive behavior. This may be of even greater importance for adolescents of ethnic minorities who are often believed to experience greater stigmatization, as well as greater distress in identity development (Oyserman, Kemmelmeier, Fryberg, Brosh, \& Hart-Johnson, 2003; Markstrom-Adams, 1990). For ethnic non-majority individuals, elevated distress has been associated with decreased feelings of personal competence and potential for growth, as well as increased feelings of general aimlessness or apathy (Spencer \& Markstrom-Adams, 1990; Swanson, Beale Spencer, Dell'Angelo, Harpalani, Spencer, 2002). It follows that adolescents who experience especially high levels of distress may be restrained from engaging in emotionfocused self-discovery, as their attention may be diverted toward coping with their distress and its consequences.

However, as adolescence is often understood as a time of increased stress, the experience of elevated levels of identity distress may be associated with a normative process of self-development. Increased exploration and experimentation may result in the individual being confronted with new identity-relevant situations and choices, which is likely distressing, though not entirely aversive or detrimental. In this way, the experience of slightly elevated identity distress may be an indicator that an adolescent is actively engaged in positive identity development, particularly if other putative factors of positive development are also found to undergo positive change. In terms of affective selfexploration, increases in personal expressiveness that co-occur with increases in identity distress may indicate more active participation in self-exploration regarding subjectivelyrelevant aspects of life. Conversely, little to no reported identity distress may suggest a 
lack of engagement in identity exploration, (potentially either or both cognitive and emotion-focused self-discovery), as self-relevant experiences are largely ignored, dismissed, or for reasons outside the control of the individual, unavailable. This may be most true for those who also show decreases in self-exploration (i.e., feelings of personal expressiveness). For these individuals, the process of self-discovery may differ, resulting in what appears to be a general apathy toward identity-related information and situations, as the perceived challenge of life may appear to be too difficult to tackle (Csikszentmihalyi, 1990), or because such engagement, for some individuals, may conflict with other self-relevant criteria, such as ethnic role expectations (see PetersonLewis \& Bratton, 2004; Fisher et al, 2002; Roderick, 2003; Spencer \& Markstrom Adams, 1990; West, 1993). Because it is not yet clear how increases or decreases in identity distress may be associated with positive self-development, even less is known with respect to intervention that may moderate distress levels. To date, no empirical data exists to evaluate the degree to which identity distress is amenable to intervention change.

Positive Development Interventions and "Negative" Developmental Factors

However, recent research does suggest that interventions that seek to promote positive gains in factors associated with positive development also serve to decrease "negative" outcomes (Garcia, 2005). As reported by the Commission on Positive Youth Development (2005), researchers at the Search Institute in Minneapolis studied what is termed developmental assets, which include external factors such as family support and adult-role models and internal factors such as commitment to learning, positive values, and sense of purpose and found these developmental assets in youth who not only show fewer problems but also display more thriving (e.g., school success, leadership, helping 
others, and physical health). Furthermore, as described by Garcia (2005), a review of the literature appears to indicate that youth development programs can promote positive domains of self-development and reduce negative outcomes, concurrently (e.g., Berkowitz \& Bier, 2004; Durlak \& Wells, 1998; Gillham \& Reivich, 2004; Greenberg \& Kusche, 1998; Hawkins, Catalano, Kosterman, Abbott, \& Hill, 1999; Solomon, Battistich, Watson, Schaps, \& Lewis, 2000; Tierney \& Grossman, 2000; Wilson, Gottfredson, \& Najaka, 2001). While these studies provide evidence to suggest that positive youth development programs can be effective in reducing negative outcomes as well as promoting positive domains of development (Garcia, 2005), to date, there has been no empirical investigation of the effect of intervention intent on promoting selfdirected positive identity development on such "negative" factors. To contribute to this literature, as well as contribute to the on-going CLP Stage II program evaluation, the current study investigated the effect self-transformative intervention strategies have on feelings of personal expressiveness and identity distress in a multi-ethnic sample of adolescent youth.

The Current Study

This study had three main (outcome) research aims and one exploratory research aim:

The first outcome research aim was to investigate the relations between participation in CLP and positive change in emotion-focused self-discovery processes (i.e., increase in feelings of personal expressiveness) and an intra-individual contextual factor believed to potentially constrain emotion-focused identity exploration (i.e., decrease in identity distress). The second outcome aim of this study was to investigate if 
a decrease in identity distress is associated with positive change in feelings of personal expressiveness. The third outcome aim of this study was to investigate the directionality of change in feelings of personal expressiveness and identity distress in participants in the treatment condition. The one exploratory aim of this study was to conduct analyses to investigate feelings of personal expressiveness as a potential mediator of an individual's sense of self (i.e., future possible self). 


\section{METHODS}

\section{Participants}

Participants for this study were drawn from archival data gathered by the Changing Lives Program from Spring 2002 to Spring 2006. First analyses involving feelings of personal expressiveness and identity distress were conducted using 214 White/Non-Hispanic, African-American, and Hispanic adolescents. Due to underrepresentation, the twenty-three White/Non-Hispanic individuals were dropped from the sample. Primary analyses were done using 191 African-American and Hispanic adolescents aged 14-19 who had completed pre-test and post-test assessments on the Personally Expressive Activities Questionnaire (PEAQ; Waterman, 1990) and the Identity Distress Scale (IDS; Berman et al., 2004). Exploratory mediation analyses were conducted using a sixty-six case subset of individuals who had also completed pre-test and post-test assessments on the Possible Selves Questionnaire-Qualitative Extension (PSQ-QE; Oyserman, 1987). The PEAQ/IDS sample consisted of one hundred eight females (sixty-six African-American, forty-two Hispanic) and eighty-three males (fortyfive African-American, thirty eight Hispanic). The PEAQ/IDS/PSQ sample consisted of forty females (twenty-eight African-American, seventeen Hispanic) and twenty-six males (twelve African-American, fourteen Hispanic).

Students who participated in the counseling intervention participated in counseling groups comprised of six to eight members who met weekly for one hour during their fall and spring semesters. All of the students in the comparison control condition were identified by school administration or school counselors as having not participated in any of the counseling and guidance programs prior to or during the 
semester in question. Students in this group served as a one-semester non-intervention (non-random) comparison condition.

\section{Participant Recruitment and Selection}

Participants were recruited through self or counselor, teacher, or administrator referrals and were required to provide signed parent consent, as well as signed student assent forms before participation. There were six types of counseling groups, which are anger management, relationships, substance abuse, and children of troubled families/abuse, and alternative lifestyles. Participants met one hour once per week. The groups were implemented through the school administrative office as part of the school's ongoing counseling program.

\section{Procedure}

Each intervention group had one group facilitator, one co-facilitator, and one or two group assistants. All groups had the same structure and format. The group facilitators were graduate level students. Students were assessed at two times (pre-, post-) with a battery of tests including the PSQ-QE and the PEAQ. Pretest assessments were administered the week preceding the beginning of participants' semester sessions and the same battery of assessments was administered for posttest, the week following the conclusion of the counseling sessions approximately 10 weeks after they began.

\section{Measures}

Background Information Form (BIF). The BIF is a questionnaire given to all study participants, asking various demographic information questions. Specifically, for this study, the BIF provided information about participants' age, gender, and ethnicity. 
The Possible Selves Questionnaire - Qualitative Extensions (PSQ-QE). The PSQQE builds on the Possible Selves Questionnaire (PSQ; Oyserman, 1987). The PSQ is a self-report questionnaire used to assess variation in possible selves, including participants' goals and motivations as well as fears and anxieties (Markus \& Nurius, 1986). Possible selves are the selves that individuals could become, or want to avoid becoming, and represent one aspect of the ability to conceptualize the self in the future. The PSQ asks participants to identify up to four expected selves and four to-be-avoided selves.

The Possible Selves Questionnaire - Qualitative Extension (PSQ-QE) is an extension of the PSQ, adapted and refined to provide a method for eliciting the expressed meaning and significance of participants' possible future selves. Specifically, participants are asked to identify up to three expected future selves and one to-be-avoided future self, and are then asked to identify their most important possible self (FPS) as well as provide an open-ended description of its meaning and significance. The meaning and significance questions are followed by three neutral probes to request secondary elaboration when necessary.

Using Relational Data Analysis (RDA; Kurtines, Lewis Arango, Kortsch, 2005) (See Appendix A), grounded theory data analytic strategies (Strauss \& Corbin, 1998) for the qualitative methods are used to code the open-ended narrative response data during each of RDA's three analytic phases. Specifically, Conceptual coding using open coding and the method of constant comparison for similarities and differences (as adapted for RDA) are used in the Conceptual Analysis phase of RDA to identify all qualitatively different categories/variables in a particular data set. Theoretical coding using open 
coding and the method of constant comparison, as adapted for RDA, are used in the Theoretical Analysis phase to identify the smallest set of theoretically meaningful (and qualitatively different) categories among the identified categories/variables.

Classification coding for consensual validation was used as a method for evaluating the concurrent validity of the theoretical categories identified during the theoretical analysis phase of RDA. The contextual and complementary use of qualitative and quantitative methods in the Research Analysis phase for evaluating qualitative research hypotheses completes the RDA. The conceptual and theoretical coding categories developed by Kortsch (2003) for PSQ responses were used: Self-Oriented, Other-Oriented, Other/Self and seven associated sub-categories, Self-Satisfying, Self-Actualizing, Altruistic, Mixed Other/Self, Self-satisfying/Altruistic, Self-Actualizing/Altruistic.

Because analyses involving FPS responses are focused on developmental change away from a purely egocentric orientation toward their hoped for future possible self, the coded responses were then recoded as either purely Self-Satisfying or Not-SelfSatisfying. Participants coded as either Self-Satisfying or Not Self-Satisfying yielded $71 \%$ inter-coder agreement. Fleiss' Kappa was calculated at .46, indicating moderate/acceptable agreement above chance.

Personally Expressive Activities Questionnaire (PEAQ, PEAQ-QE). The PEAQ (Waterman, 1995) assesses change in the personal and prosocial content of participants' life goals and change in the degree to which they experience the pursuit of these goals as personally satisfying and expressive of their unique potentials. The PEAQ asks participants to identity three life goals that are important to them and rate each goal on 
fourteen 7-point Likert items. Six of the items rate the goals for personal expressiveness, six for enjoyment, and two for flow challenge (Csikszentmihalyi, 1990).

The PEAQ yields quantitative results that focus on participants' life goals. Specifically, the PEAQ yields three quantitative scores with respect to these life goals: personal expressiveness (PE), hedonic enjoyment (HE), and flow challenge (FLOW-C). Hedonic enjoyment refers to feelings of enjoyment that are not deemed to be personally expressive. Flow challenge refers to the individual's perception of fit between their skill levels and the contextual challenges they describe. Alphas for PE and HE have been reported as .77 and .90 , respectively. The PEAQ provides only two items per goal regarding the FLOW-C scale.

The Personally Expressive Activities Questionnaire (PEAQ-QE) is an extension of the PEAQ, adapted and refined to provide a method for eliciting the expressed meaning and significance of participants' life goals. Specifically, participants are asked to identify up to asked to identify their most important life goal as well as provide an openended description of its meaning and significance. The meaning and significance questions are followed by three neutral probes to request secondary elaboration when necessary. The open-ended narrative response data remain to be coded using RDA (Kurtines et al., in press).

Identity Distress Scale (IDS). The IDS (Berman et al., 2004) is a 10-item scale based on criteria for Identity Disorder as defined in the DSM-III-R (APA, 1983). Using a 5-point Likert-type scale, seven questions ask to what degree the participant has recently been upset, distressed, or worried over the following issues: long-term goals, career choices, friendships, sexual orientation and behavior, religion, values and beliefs, and 
group loyalties. Two general questions ask participants to indicate their global levels of distress about the issues raised in the previous seven questions, using the same 5-point scale, with scores representing more distress (discomfort, interference with life). One question asks about duration of distress over these issues. Cronbach's standardized alpha for IDS items 1-9 has been previously reported at .80 (Hernandez, Montgomery, \& Kurtines, 2006).

The Identity Distress Scale is most often scored where individuals are considered to meet diagnosis if they rate "upset, distress, or worry" in at least three of the seven identity issues at a level of "often" or "almost always," with overall distress or interference ratings as "moderate" or higher, and duration of distress as being 3 months or more. For this study, however, only responses reflecting their number one distressor were considered. Analyses were conducted using computed intervention and comparison group means. Distress scores of three or above, i.e., moderate to very severe, were considered of clinical significance.

Analyses

Relational Data Analysis. Appendix A contains a detailed theoretical and procedural description of a full Relational Data Analysis.

Structural Equation Modeling Indices of Model Fit. Following the recommendations of Bollen and Long (1993), a variety of global fit indices were used to evaluate model fit, including indices of absolute fit, indices of relative fit and indices of fit with a penalty function for lack of parsimony. First, the chi-square and its probability value ( $p$-value) were examined. The higher the $p$-value, the closer the fit between the hypothesized model and model fit (Byrne, 2001), with a target $p$-value of greater than 
.05 . The goodness of fit index (GFI) was used as a measure of the relative amount of variance and co-variance explained by the hypothesized model. A GFI value of greater than .90 was used to indicate model fit. The comparative fit index (CFI) was also used. The CFI is an index of fit based on the comparison of the hypothesized model with the independence model. A CFI value of greater than .95 was used to indicate model fit. The root mean square error of approximation (RMSEA) accounts for the error of approximation in the population. An RMSEA of less than .08 was used to indicate model fit.

Mediation Analysis. Mediation analyses were conducted in line with recommendations by Baron and Kenny (1986). Specifically, in addition to establishing that an intervention has an outcome effect (the efficacy test), mediation analyses also involve determining whether the intervention also has an effect on the hypothesized mediator (the specificity test). Mediation analyses must also demonstrate a relationship between the hypothesized mediator and the outcome before finally demonstrating no (or decreased) intervention effects on the outcome, while controlling for the effects of the hypothesized mediator.

\section{Research Aims}

Within the framework of the CLP Stage II evaluation, this study had three outcome research aims and one exploratory research aim. The three outcome research aims were evaluated using a full sample of individuals that had completed pre- and posttests on PE and ID. The exploratory research aim was evaluated using a subset of the $\mathrm{PE} / \mathrm{ID}$ sample who had also completed pre- and post-tests on FPS. Both the outcome and 
exploratory research aims were evaluated using structural equation modeling (SEM) techniques.

Outcome Research Aim 1 (Efficacy Analyses)

The first aim of this study was to investigate whether participation in the CLP intervention was associated with statistically significant positive change in feelings of personal expressiveness and reduction in levels of identity distress relative to the comparison condition. This question is designed to replicate and extend the findings of Albrecht (2005a) and Hernandez, Montgomery and Kurtines (2006) with respect to the effectiveness of the Changing Lives Program. Two specific outcome research hypotheses were tested.

Outcome Research Hypothesis 1.1. Participants in the intervention condition will show a statistically significant positive change in feelings of personal expressiveness (PE) relative participants in the comparison condition.

Outcome Research Hypothesis 1.2. Participants in the intervention condition will show a statistically significant reduction in levels of identity distress as measured by the IDS relative to comparison condition participants. Outcome Research Aim 2 (Moderation Analyses)

The purpose of Research Aim 2 is to investigate three exogenous interpersonal contextual factors (age/stage, gender, and ethnicity) as potential moderators of intervention effectiveness (i.e., changes in levels of personal expressiveness and identity distress). One specific outcome research hypotheses was tested.

Outcome Research Hypothesis 2. The effectiveness of the intervention condition will be moderated by the interpersonal contextual variables of age, gender, and/or 
ethnicity such that there will be statistically significantly difference in intervention response by the categories of the interpersonal contextual variables (e.g., 14-16 year olds versus 17-19 year olds; male versus female; Hispanic/Latino versus Black/AfricanAmerican).

Outcome Research Aim 3 (Directionality of Effects)

The purpose of Research Aim 3 was an investigation the directional relation between feelings of personal expressiveness and feelings of identity distress in general and the specific question of whether positive change in personal expressiveness is related to a reduction of identity distress. One specific outcome research hypotheses was tested.

Outcome Research Hypothesis 3.1. Positive change in feelings of personal expressiveness will be associated with reduction in feelings of identity distress. Exploratory Research Aim 1 (Mediation Analyses)

The fourth research aim was conducted as an exploratory mediation analysis using a sample subset of that used in the Research Aims 1-3. The purpose of research Aim 4 was to evaluate personal expressiveness as a potential mediator of future possible selves. Three specific exploratory research hypotheses were tested:

Exploratory Research Hypothesis 1.1. (Differential Treatment Response) Participants in the intervention condition will show a statistically significant positive change in FPS relative to the comparison condition.

Exploratory Research Hypothesis 1.2. (Specificity of Mediation Effect) Participants in the intervention condition will show a statistically significant positive change in PE relative to the comparison condition. 
Exploratory Research Hypothesis 1.3. (Mediation of Outcome Effect) Positive change in $\mathrm{PE}$ in intervention participants will be statistically significantly related to positive change in FPS.

\section{RESULTS \\ Model 1 Fit Analysis}

Model 1 provided results for the main outcome (effectiveness) analyses, moderation analyses, and directionality of effect for the full sample. The fit of Model 1 (visually presented in Figure 2) was evaluated with AMOS 6.0 using the sample covariance matrix as input and a maximum likelihood solution. The model is statistically overidentified. Prior to analysis, and within each group, data for the continuous variables were evaluated for outliers, by examining leverage statistics for each individual; an outlier was defined as an individual with a leverage score four times greater than the mean leverage. No outliers were found. The data was also assessed for missingness. Dummy variables were created for missing data and correlated with gender, ethnicity, age, and school location. Missing data was not strongly correlated with any of these variables; Little's MCAR test was also performed and found to be non-significant, $\chi^{2}=$ $8.796, \mathrm{df}=10, p=.552$, further suggesting that the data is missing at random. Preliminary model analyses were performed using missing data that were imputed using ExpectationMaximization based imputation, as performed by the computer program Amelia II (Honaker, Joseph, and Blackwell, 2006). All final analyses were performed using the Full Information Maximum Likelihood (FIML) method within AMOS 6.0. The data was also assessed for non-normality. Both the data for feelings of personal expressiveness and identity distress showed kurtosis and skewness within acceptable ranges 
Figure 3: Final SEM Model for Efficacy, Moderation, and Directionality Analyses

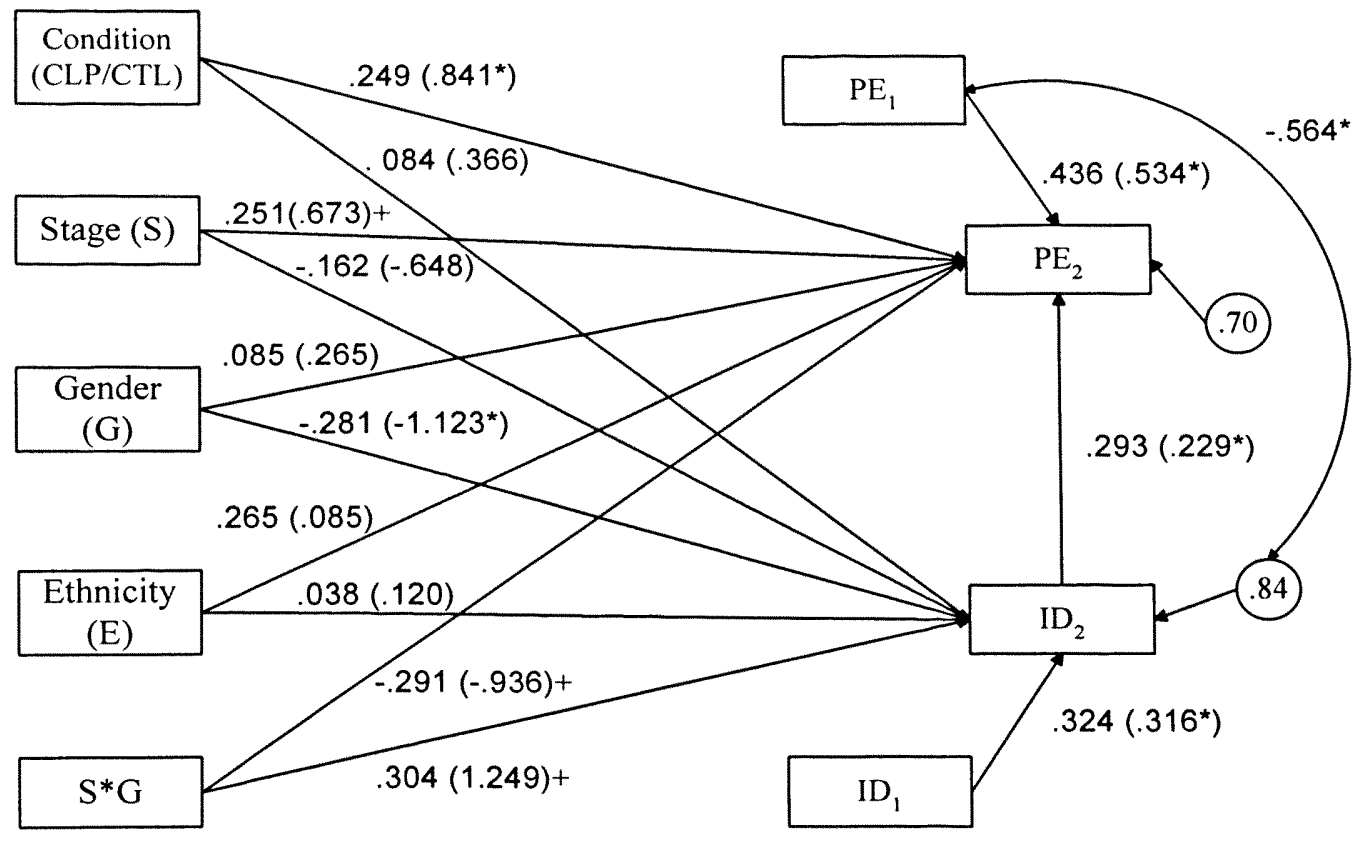

Figure 3: Rectangles are observed (measured) variables and circles are standardized error variances, values in parentheses are unstandardized path coefficients, values not in parentheses are standardized path coefficients, straight lines with arrows are presumed causal paths, double-headed curved lines are correlations. All exogenous variables were assumed correlated, but such correlations were omitted from the diagram to reduce clutter. ${ }^{*}$ denotes significance at $p<.05$. $†$ denotes marginal significance.

Outcome Research Hypotheses $1.1 \& 1.2$ (Effectiveness and Moderation Analyses)

Following the logic of Raush, Maxwell, and Kelly (2003), the scores of the baseline measures ( $\mathrm{PE}_{1}, \mathrm{ID}_{1}$, see Figure 3$)$ were used for the analysis of covariance of an quasi-experimental outcome design with two waves of assessment (pretest, posttest) to evaluate Outcome Research Hypotheses 1.1 \& 1.2, i.e., whether CLP was associated with positive change in feelings of personal expressiveness and reduction of identity distress 
relative to the WLC. Specifically, $\mathrm{C}$ was defined (Condition) as a two-valued dummy variable (scored 1 or 0 ) for the two intervention conditions (CLP vs. CCTL). By design, difference in this variable (Intervention vs. Comparison) was hypothesized to be related to differential outcome (positive change in $\mathrm{PE}$ and reduction in ID) at posttest $\left(\mathrm{PE}_{2}, \mathrm{ID}_{2}\right)$ controlling for pretest $\left(\mathrm{PE}_{1}, \mathrm{ID}_{1}\right)$. The hypothesized differences were evaluated using covariate-adjusted change in which the baseline (pre-test) measure of the outcome and the outcome at the posttest are strategically used as covariates to define different features of change (Raush et al., 2003).

Three exogenous interpersonal contextual factors covariates were included in the analysis, (S) Stage, (G) Gender, and (E) Ethnicity, in the analysis of outcome as measured at pretest $\left(S_{1} G_{1} E_{1}\right)$ and all possible interaction terms (i.e., $C_{1} \times S_{1}, C_{1} \times G_{1}$, $\mathrm{C}_{1} \mathrm{xE}_{1}, \mathrm{C}_{1} \mathrm{x} \mathrm{S}_{1} \times \mathrm{G}_{1}, \mathrm{C}_{1} \mathrm{x} \mathrm{S}_{1} \times \mathrm{E}_{1} \ldots$. etc.). Figure 3 excludes all but the three basic covariates and the single significant interaction term $\left(\mathrm{S}_{1} \times \mathrm{E}_{1}\right)$ so as to reduce clutter.

As can be seen from Figure 3, the path coefficients for the effect of Condition (C) on $\mathrm{PE}_{2}$ and $\mathrm{ID}_{2}$ provided support for Outcome Research Hypotheses 1.1 but not 1.2, i.e., that CLP was related to positive change in personal expressiveness and but not in the reduction of identity distress relative to the WLC. From Figure 3 it can be seen that the path coefficient for the effect of Condition on $\mathrm{PE}_{2}$ (holding $\mathrm{PE}_{1}$ constant) showed a statistically significant change in feelings of personal expressiveness (PE) relative participants in the comparison condition. As the results indicate, the path coefficient was statistically significant $(p<.002)$, with a value of .841 . The intervention group changed 0.841 units more than the comparison group on $\mathrm{PE}_{2}, p<.002$. The path coefficient for the effect of Condition on $\mathrm{ID}_{2}$ (holding $\mathrm{ID}_{1}$ constant), in contrast, did not show a significant 
reduction in identity distress (ID). In fact, although not significant, the direction of change in identity distress in intervention participants increased relative to participants in the comparison condition. As the results indicate, the intervention group increased 0.366 units relative to the comparison group on $\mathrm{ID}_{2}, p<.002$.

Outcome Research Hypotheses 2.1 (Directionality of Effects)

Path ID2 > PE2 reflect contemporaneous change and estimate the extent to which changes in identity distress are associated with changes in personal expressiveness at the posttest. This path coefficient was statistically significant (path $=.229, p<.002$ ), indicating that positive change in personal expressiveness was associated with significant increases in identity distress, across both conditions.

Three marginally significant paths were also found. The 2-way interaction stage $\mathrm{x}$ gender yielded a path coefficient of $1.249, p<.087$ on $\mathrm{ID}_{2}$, and the coefficient for $\mathrm{PE}_{2}$ was $-.936, p<.067$. Finally, stage yielded a path coefficient on $\mathrm{PE}_{2}$ of $.673, p<.070$. To examine the marginally significant effects as well as the significant effects more closely, mean scores for each subgroup were calculated, and these are detailed in the next section. Subgroup Mean Differences: Feelings of Personal Expressiveness

Pre- to post- change was evaluated for the treatment and comparison conditions separately for both PE and ID. Recalling that PE scores range from 1 to 7 , there was no statistically significant change in PE for the treatment group; however, the comparison group showed a significant decline in its mean PE score from 5.409 to $4.555, \chi^{2}=10.68, p$ $<.001$. To further evaluate change in PE scores, and to evaluate any trends in the data, mean PE scores were calculated for each participating subgroup, defined by age (i.e., ages 14-16 and 17-19), gender, and ethnicity. 
Table 1

Descriptive Statistics for Model 1 Variables $(N=191)$

\begin{tabular}{|c|c|c|c|c|c|c|c|c|}
\hline \multirow{2}{*}{ Variable } & \multicolumn{2}{|c|}{$\bar{M}$} & \multicolumn{2}{|c|}{ SD } & \multicolumn{2}{|c|}{ Skewness } & \multicolumn{2}{|c|}{ Kurtosis } \\
\hline & Pre & Post & Pre & Post & Pre & Post & Pre & Post \\
\hline $\begin{array}{l}\text { Feelings of Personal } \\
\text { Expressiveness (PE) }\end{array}$ & 5.39 & 5.08 & 1.27 & 1.58 & -.89 & -.67 & .35 & .17 \\
\hline Identity Distress (ID) & 2.83 & 3.33 & 2.01 & 1.97 & .19 & -.09 & -.66 & -.39 \\
\hline Continuous Variables & \multicolumn{2}{|c|}{$\mathrm{M}$} & \multicolumn{2}{|c|}{ SD } & \multicolumn{2}{|c|}{ Range } & & \\
\hline Age (years) & \multicolumn{2}{|c|}{16.44} & \multicolumn{2}{|c|}{1.16} & \multicolumn{2}{|c|}{$14-19$} & & \\
\hline
\end{tabular}

Table 2 shows mean PE scores for all participating subgroups, as well as a comparison between the intervention and comparison conditions. Comparing intervention versus comparison, there is a negligible difference in mean PE scores at pre-test. At posttest, all intervention subgroups show higher PE scores relative to comparisons.

Comparing the intervention versus comparison groups at post-test, 14-16 year old intervention participants were found to have mean $\mathrm{PE}_{2}$ scores approximately .82 units

Table 2

PE Mean Comparisons, Intervention vs. Comparison

\begin{tabular}{lcccccccc}
\hline & \multicolumn{3}{c}{ African-American 14-16 yrs } & \multicolumn{3}{c}{ Hispanic 14-16 yrs } \\
\cline { 2 - 9 } & \multicolumn{2}{c}{ Males } & \multicolumn{2}{c}{ Females } & \multicolumn{2}{c}{ Males } & \multicolumn{2}{c}{ Females } \\
\cline { 2 - 9 } & Pre- & Post- & Pre- & Post- & Pre- & Post- & Pre- & Post- \\
\hline Treatment (T) & 5.36 & 5.80 & 5.61 & 5.36 & 5.22 & 5.68 & 5.47 & 5.24 \\
Comparison (C) & 5.36 & 4.98 & 5.49 & $4.55^{*}$ & 5.22 & 4.86 & 5.35 & $4.43^{*}$ \\
T- C & .00 & .83 & .12 & .82 & .00 & .83 & .12 & .82 \\
\hline & \multicolumn{1}{c}{ African-American $17-19 y r s$} & Hispanic 17-19 yrs & \\
\hline Treatment (T) & 4.93 & 5.25 & 5.69 & .59 & 4.79 & 5.13 & 5.55 & 5.47 \\
Comparison (C) & 5.22 & $4.30^{*}$ & 5.87 & $.65^{*}$ & 5.08 & 4.18 & 5.73 & $4.52^{*}$ \\
T- C & -.29 & .96 & -.17 & .95 & -.29 & .95 & -.17 & .95 \\
\hline & & & & & \multicolumn{5}{c}{ *significance $p<.05$}
\end{tabular}

higher relative to comparison, with no differences with regard to gender, or ethnicity. 17-

19 year old intervention participants show a similar trend, with post-test $\mathrm{PE}_{2}$ scores approximately .95 units higher than non-intervention comparisons. 
PE mean change scores for each subgroup are displayed in Tables 3 below. Male treatment participants from both age groups and ethnicities show non-significant pre- to post- increases in PE scores, while males in the comparison condition show an overall non-significant decline in PE scores; more specifically, African-American male 17-19 year olds in the Comparison group show a marginally significant decrease in PE scores of .924 units, $\chi^{2}=3.8, p<.051 .17-19$ year old Hispanic male comparisons show a marginally significant decline in PE scores of approximately .904 units, $\chi^{2}=3.6, p<058$.

Table 3

PE Mean Change Scores, Pre- to Posttest

\begin{tabular}{|c|c|c|c|c|c|c|c|c|c|c|c|c|}
\hline & \multicolumn{6}{|c|}{ African-American 14-16 yrs } & \multicolumn{6}{|c|}{ Hispanic 14-16 yrs } \\
\hline & \multicolumn{3}{|c|}{ Males } & \multicolumn{3}{|c|}{ Females } & \multicolumn{3}{|c|}{ Males } & \multicolumn{3}{|c|}{ Females } \\
\hline & Pre- & Post- & $\Delta$ & Pre- & Post- & $\Delta$ & Pre- & Post- & $\Delta$ & Pre- & Post- & $\Delta$ \\
\hline $\mathrm{T}$ & 5.36 & 5.80 & .45 & 5.61 & 5.36 & -.25 & 5.22 & 5.68 & .47 & 5.47 & 5.24 & -.23 \\
\hline \multirow[t]{2}{*}{$\mathrm{C}$} & 5.36 & 4.98 & -.38 & 5.49 & 4.55 & $-.95 *$ & 5.22 & 4.86 & -.36 & 5.35 & 4.43 & $-.93 *$ \\
\hline & \multicolumn{6}{|c|}{ African-American 17-19yrs } & \multicolumn{6}{|c|}{ Hispanic 17-19 yrs } \\
\hline $\mathrm{T}$ & 4.93 & 5.25 & .33 & 5.69 & 5.59 & -.10 & 4.79 & 5.13 & .34 & 5.55 & 5.47 & -.08 \\
\hline $\mathrm{C}$ & 5.22 & 4.23 & $-.92 *$ & 5.87 & 4.65 & $-1.22 *$ & 5.08 & 4.18 & -.90 & 5.73 & 4.52 & $-1.20 *$ \\
\hline
\end{tabular}

Female treatment participants of both age groups and ethnicities show nonsignificant pre- to post- PE score declines, while female comparison group participants for both ages and ethnicities show significant pre- to post-test declines. Specifically, 1416 year old African-American female comparisons show a .948 unit decline, $\chi^{2}=4.7, p<$ .03. 14-16 year old Hispanic female comparisons show a .929 unit decline, $\chi^{2}=4.4, p<$ .035. 17-19 year old African-American female comparisons show a 1.222 unit decline, $\chi^{2}$ $=5.4, p<.02 .17-19$ year old Hispanic female comparisons show a decline in PE scores of 1.203 units, $\chi^{2}=3.95, p<.047$. 
Pre- to post-test change was evaluated for ID. The treatment group showed a nonsignificant increase in ID from 2.945 to 3.374 units. The comparison group showed a non-significant increase in ID from 2.554 to 3.100 units. To examine more closely the data for subgroup differences, mean ID scores for each subgroup were calculated.

Table 4 reports mean scores of Identity Distress (ID). Male intervention participants from both age groups and ethnicities show higher levels of identity distress at both pre- and post-test relative to comparisons. 14-16 year old treatment participants show higher ID scores approximately .56 units higher at pre-test and 1.37 units higher at post-test, relative to comparison. 14-16 year old male African-American comparisons show a slight non-significant decrease, while Hispanic male comparisons of the same age show no change pre- to post. Within the older age bracket, the difference between the Table 4

ID Mean Comparisons, Intervention vs. Comparison

\begin{tabular}{|c|c|c|c|c|c|c|c|c|}
\hline & \multicolumn{4}{|c|}{ African-American 14-16 yrs } & \multicolumn{4}{|c|}{ Hispanic $14-16$ yrs } \\
\hline & \multicolumn{2}{|c|}{ Males } & \multicolumn{2}{|c|}{ Females } & \multicolumn{2}{|c|}{ Males } & \multicolumn{2}{|c|}{ Females } \\
\hline & Pre- & Post- & Pre- & Post- & Pre- & Post- & Pre- & Post- \\
\hline Treatment (T) & 2.86 & 3.28 & 2.77 & 3.17 & 3.11 & 3.89 & 3.01 & 3.78 \\
\hline Comparison (C) & 2.30 & 1.91 & 2.13 & 2.70 & 2.55 & 2.52 & 2.38 & 3.30 \\
\hline \multirow[t]{2}{*}{$\mathrm{T}-\mathrm{C}$} & .56 & 1.37 & .63 & .47 & .56 & 1.37 & .63 & .48 \\
\hline & \multicolumn{4}{|c|}{ African-American 17-19yrs } & \multicolumn{4}{|c|}{ Hispanic $17-19$ yrs } \\
\hline Treatment (T) & 2.72 & 3.48 & 3.07 & 2.44 & 2.97 & $4.09^{*}$ & 3.32 & 3.04 \\
\hline Comparison $(\mathrm{C})$ & 2.65 & 3.25 & 2.92 & 3.10 & 2.90 & 3.85 & 3.17 & 3.70 \\
\hline $\mathrm{T}-\mathrm{C}$ & .07 & .24 & .15 & -.66 & .07 & .24 & .15 & -.66 \\
\hline
\end{tabular}

treatment and comparison conditions narrows. Male treatment and comparison participants show virtually no difference at pre-test, and only a small .24 unit difference 
at post-test. However, the male Hispanic treatment group shows a marginally significant increase pre- to post- of 1.117 units, $\chi^{2}=3.6, p<.059$. Hispanic male comparisons show a similar unit increase, though the change is non-significant. 14-16 year old female intervention participants show mean ID scores approximately .63 units higher at pre-test than comparisons. At post-test, the female treatment group continues to show higher levels of ID, though the increase pre- to post- is less than that of the comparison group. Notably, 17-19 year old African-American and Hispanic female treatment participants show a decline in ID scores relative to comparison; African-American female comparison show little change in ID scores, while Hispanic females show an increase. Overall, the largest increase in ID occurs for Hispanic male treatment participants, while the largest decrease in ID occurs for 17-19 year old female treatment participants of both ethnicities. ID mean change scores for each subgroup are displayed in Table 5 below.

Table 5

ID Mean Change Scores, Pre-to Post-test

\begin{tabular}{|c|c|c|c|c|c|c|c|c|c|c|c|c|}
\hline & \multicolumn{6}{|c|}{ African-American 14-16 yrs } & \multicolumn{6}{|c|}{ Hispanic 14-16 yrs } \\
\hline & \multicolumn{3}{|c|}{ Males } & \multicolumn{3}{|c|}{ Females } & \multicolumn{3}{|c|}{ Males } & \multicolumn{3}{|c|}{ Females } \\
\hline & Pre- & Post- & $\Delta$ & Pre- & Post- & $\Delta$ & Pre- & Post- & $\Delta$ & Pre- & Post- & $\Delta$ \\
\hline $\mathrm{T}$ & 2.859 & 3.28 & .42 & 2.77 & 3.17 & .41 & 3.11 & 3.89 & .78 & 3.01 & 3.78 & .76 \\
\hline $\mathrm{C}$ & 2.300 & 1.91 & -.39 & 2.13 & 2.70 & .56 & 2.55 & 2.52 & -.03 & 2.38 & 3.30 & .92 \\
\hline & \multicolumn{6}{|c|}{ African-American 17-19yrs } & \multicolumn{6}{|c|}{ Hispanic $17-19$ yrs } \\
\hline $\mathrm{T}$ & 2.722 & 3.48 & .76 & 3.07 & 2.43 & -.64 & 2.97 & 4.09 & $1.12 *$ & 3.32 & 3.04 & .28 \\
\hline $\mathrm{C}$ & 2.649 & 3.25 & .60 & 2.92 & 3.10 & .17 & 2.90 & 3.85 & .95 & 3.17 & 3.70 & .53 \\
\hline
\end{tabular}

Table 6 lists relative percentages of participant reports of the domain of life causing the greatest level of identity distress at pre- and post-test. At pre-test, $48 \%$ of intervention participants reported distress as none to mild and $52 \%$ reported distress as moderate to very severe. At post-test severity of distress increased slightly, with $43 \%$ 
reporting distress as none to mild and $57 \%$ reporting distress as moderate to very severe. For the comparison group at pre-test, $67 \%$ reported distress as none to mild and $33 \%$ reported levels of distress as moderate to severe. At post-test, $64 \%$ reported distress as none to mild and $36 \%$ reported distress as moderate to very severe.

Table 6

Relative Percentages of Reported Domains of Greatest Identity Distress

\begin{tabular}{lcccccc}
\hline & \multicolumn{3}{c}{ Intervention } & \multicolumn{3}{c}{ Comparison } \\
\cline { 2 - 7 } & Pre & Post & $\%$ change & Pre & Post & $\%$ change \\
\hline Long Term Goals & 19 & 30 & +11 & 50 & 31 & -19 \\
Career & 5 & 22 & +17 & 0 & 9 & +9 \\
Friendship Patterns & 28 & 19 & -7 & 25 & 22 & -3 \\
Sexual Orientation/ Behavior & 7 & 0 & -7 & 0 & 11 & +11 \\
Religion & 5 & 1 & -4 & 8 & 3 & -5 \\
Moral/Ethical Decisions or & 13 & 20 & +7 & 8 & 0 & -8 \\
Value System & 23 & 8 & -15 & 9 & 24 & +13 \\
Group Loyalties & & & & & &
\end{tabular}

Model 2 Exploratory Mediation Analyses

Model 2 provided results for the exploratory analyses to examine feelings of personal expressiveness as a potential mediator of future possible selves. Selfconstruction processes are illustrated to recall the more complete transformative model of identity development mentioned previously, though no measure of self-construction was included in these analyses. The fit of this model was tested using the same procedures as Model 1. Model 2 contained no additional missing data. Model 2 was originally evaluated including all possible interaction effects between the moderating factors, condition, stage, gender, and ethnicity. No significant three or four-way interactions were found, and were thus dropped from the final model. As the previous model indicated no statistically significant treatment effect on $\mathrm{ID}_{2}$, this path was also omitted. The final 
model tested yielded a good fit to the data. The overall chi square test of model fit was statistically non-significant, $\chi^{2}(9)=7.142, p<.622$. The Root Mean Square Error Approximation (RMSEA) was .000. The $p$-value for the test of close fit was .728 . The Comparative Fit Index (CFI) was 1.00.

As in Figure 3, Figure 4 shows a significant treatment effect on $\mathrm{PE}_{2}$, though slightly reduced. A marginally significant Stage $\mathrm{x}$ Ethnicity effect was found on FPS of .491 units, $p<.052$, while the previously significant effect of $\mathrm{ID}_{2}$ on $\mathrm{PE}_{2}$ was no longer

Figure 4: Exploratory Mediation Model (Research Aim 4)

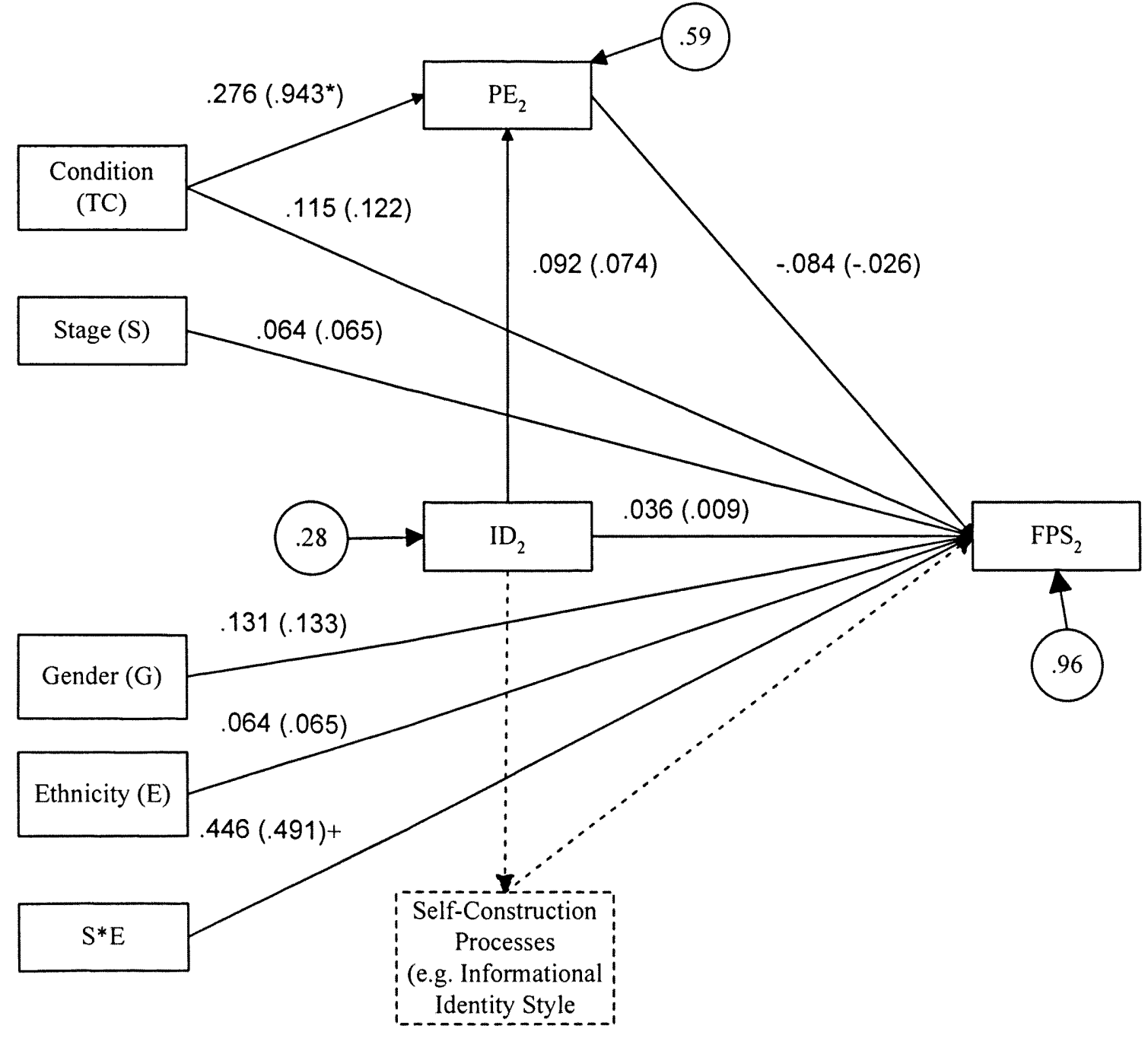


present. Figure 4: Exploratory Mediation Model: Personal Expressiveness (PE), Identity Distress (ID), Feelings and Future Possible Selves (FPS). Rectangles are observed (measured) variables and circles are standardized error variances, values in parentheses are unstandardized path coefficients, values not in parentheses are standardized path coefficients, straight lines with arrows are presumed causal paths, double-headed curved lines are correlations. A measure of self-construction is not included, but is represented as a dotted rectangle to illustrate a full model as proposed in Figure 1. All exogenous variables were assumed correlated, but were omitted from the diagram to reduce clutter. * denotes significance at $p<.05 .+$ denotes marginal significance.

\section{Subgroup Mean Differences: Future Possible Selves}

Table 7 compares mean scores from pre- to post- for the intervention and comparison groups. At pretest, there is a slight, non-significant difference between the intervention and comparison groups. Recalling that the Self-Satisfying orientation equaled one and non-Self-Satisfying equaled zero, at posttest, comparison participants were found to have a slightly less self-satisfying orientation.

To more closely examine these subgroup differences, $\mathrm{FPS}_{2}$ mean scores were calculated as defined by (intervention vs. comparison), stage (i.e., ages 14-16 and 17-19), gender, and ethnicity. Mean change was tested for significance, using a nested chi square test, with $\chi^{2}>3.84$ as the threshold for significance. No significant pre- to post- change was found, however the trend for the majority of participants, intervention and comparison, shows mean change staying relatively the same, or moving toward a more non-Self-Satisfying orientation. Exceptions to this trend are African-American male and 
female treatment participants from both age groups, who show change in the opposite direction, toward a more Self-Satisfying orientation.

Table 7

$\mathrm{FPS}_{2}$ Mean Comparisons, Intervention vs. Comparison

\begin{tabular}{lcccccccc}
\hline & \multicolumn{3}{c}{ African-American 14-16 yrs } & \multicolumn{3}{c}{ Hispanic 14-16 yrs } \\
\cline { 2 - 9 } & \multicolumn{2}{c}{ Males } & \multicolumn{2}{c}{ Females } & \multicolumn{2}{c}{ Males } & \multicolumn{2}{c}{ Females } \\
\cline { 2 - 9 } & Pre- & Post- & Pre- & Post- & Pre- & Post- & Pre- & Post- \\
\hline Treatment (T) & .56 & .66 & .50 & .57 & .69 & .67 & .62 & .59 \\
Comparison (C) & .65 & .60 & .59 & .52 & .78 & .62 & .71 & .53 \\
T-C & -.09 & .05 & -.09 & .05 & -.09 & .05 & -.09 & .05 \\
\hline & \multicolumn{3}{c}{ African-American 17-19yrs } & \multicolumn{3}{c}{ Hispanic $17-19$ yrs } \\
\hline Treatment (T) & .47 & .50 & .41 & .41 & .60 & .52 & .53 & .43 \\
Comparison (C) & .56 & .45 & .50 & .36 & .69 & .47 & .62 & .38 \\
T-C & -.09 & .05 & .09 & .05 & -.09 & .05 & -.09 & .05 \\
\hline
\end{tabular}

Table 8 lists $\mathrm{FPS}_{2}$ mean change for all subgroups. As noted above, AfricanAmerican intervention participants show a slight mean change toward a more SelfSatisfying orientation relative to their peers.

Table 8

$\mathrm{FPS}_{2}$ Mean Change Scores

\begin{tabular}{cccccccccccccc}
\hline & \multicolumn{3}{c}{ African-American 14-16 yrs } & \multicolumn{5}{c}{ Hispanic 14-16 yrs } \\
\cline { 2 - 14 } & \multicolumn{3}{c}{ Males } & \multicolumn{3}{c}{ Females } & \multicolumn{3}{c}{ Males } & \multicolumn{3}{c}{ Females } \\
\cline { 2 - 13 } & Pre- & Post- & $\Delta$ & Pre- & Post- & $\Delta$ & Pre- & Post- & $\Delta$ & Pre- & Post- & $\Delta$ \\
\hline $\mathrm{T}$ & .56 & .66 & -.09 & .50 & .57 & -.07 & .69 & .67 & .01 & .62 & .59 & .04 \\
$\mathrm{C}$ & .65 & .60 & .05 & .59 & .52 & .07 & .78 & .62 & .12 & .71 & .53 & .18 \\
\hline \multicolumn{4}{c}{ African-American $17-19$ yrs } & & \multicolumn{5}{c}{ Hispanic 17-19 yrs } \\
\hline $\mathrm{T}$ & .47 & .50 & -.03 & .41 & .41 & -.01 & .60 & .52 & .08 & .53 & .43 & .10 \\
$\mathrm{C}$ & .56 & .45 & .12 & .50 & .36 & .14 & .69 & .47 & .22 & .62 & .38 & .24 \\
\hline
\end{tabular}

Comparison group participants of both age groups, ethnicities, and genders were found to have the largest mean changes toward the non-Self-Satisfying orientation. The largest mean change of .24 units was found to occur for Hispanic female comparison group. 


\section{DISCUSSION}

This study had three main research (outcome) aims and one exploratory research aim. The first research aim was to investigate whether participation in the CLP intervention was associated with an increase in feelings of personal expressiveness and a decrease in reported levels of identity distress relative to the comparison condition. The second aim was to investigate three exogenous interpersonal contextual factors (age/stage, gender, and ethnicity) as potential moderators of intervention effectiveness (i.e., changes in levels of personal expressiveness and identity distress). The third research aim was to investigate the directionality of effects, specifically to see if a decrease in identity distress was associated with an increase in feelings of personal expressiveness. The exploratory research aim was to evaluate personal expressiveness as a potential mediator of future possible selves using structural equation modeling.

With respect to the first research aim, the results of this study provided support for the hypothesis that participation in the CLP's intervention was associated with statistically significant differences between intervention and comparison conditions in change in feelings of personal expressiveness from pre to posttest, but not identity distress. With respect to the second research aim, intervention effects on feelings of personal expressiveness were not moderated by age, gender, or ethnicity. With respect to research aim three, change in identity distress was found to be associated with change in feelings of personal expressiveness. However, unexpectedly, as feelings of personal expressiveness increased, identity distress increased, as well. With respect to the exploratory investigation of feelings of personal expressiveness as a mediator of future possible selves, findings were inconclusive. 
Feelings of Personal Expressiveness

The first research aim was to investigate whether participation in the CLP intervention was associated with an increase in feelings of personal expressiveness and a decrease in reported levels of identity distress relative to the comparison condition. Participation in the intervention condition was found to be associated with only slight changes in PE scores. Males were found increase slightly (approximately .47 units) and females were found to decrease slightly (approximately .23 units). Neither changes were statistically significant. However, examination of the comparison group revealed that those who did not participate in the CLP intervention experienced statistically significant declines in PE scores over time. The declines were most pronounced in females (.904 to 1.22 units, $p<.05)$, and older males (.924 units, $p<.05)$.

\section{Identity Distress}

Participation in the intervention condition was not found to be associated with statistically significant change in ID scores at posttest. Examination of pre- and posttest mean scores for participating subgroups revealed that except for younger male comparisons and older females, ID scores tended to increase for members of both conditions (between .406 and 1.117 units). This increase was marginally significant for older Hispanic males in the treatment condition (1.12 units, $p<.07)$. Contrary to the general trend, older female intervention participants' ID scores were found to decrease slightly over time (approximately .66 units), though the decrease was non-significant. The same is true for younger comparison males (.03 to .39 unit declines). 
Research Aim 2: Exogenous Moderators of Intervention Effectiveness

The second research aim was to investigate three exogenous interpersonal contextual factors (age/stage, gender, and ethnicity) as potential moderators of intervention effectiveness (i.e., changes in levels of personal expressiveness and identity distress). These factors were not found to moderate intervention outcomes.

Independent of the intervention effect, stage and a stage by gender interaction were found to moderate PE and ID at post-test. A stage effect was found $(.673, p<.067)$ where females PE post-test scores decrease relative to males, and a two-way stage by gender interaction effect $(.936, p<.087)$ was found where older females experience the greatest declines in PE scores over time. A marginally significant two-way stage by gender effect $(1.249 p<.087)$ was found where older males experience the greatest increase in ID scores over time.

Research Aim 3: Directionality of Effects

The third research aim was to evaluate directionality of change between identity distress and feelings of personal expressiveness. Contrary to expectations, feelings of personal expressiveness were found to increase as identity distress increased (.229 units, $p<.05)$. Though mean distress scores did not exceed the "moderate" level, these findings suggest that as participants' feelings of personal expressiveness increased, so did their level of discomfort with specific identity-relevant domains of life. This may suggest that the process of emotion-focused self-discovery brings with it challenges that are experienced as distressing, though not aversively so. Or, these findings may suggest that as individuals are increasingly beginning to explore identity-relevant information on an 
affective level, changes are occurring with respect to the aspects of life they find to be of the most concern and distress.

This perspective may be evidenced by the domains of life cited by the intervention and comparison groups from pre- to posttest. Examining the overall change trends, the intervention condition reported a $28 \%$ increase in the number of individuals who reported future-oriented distress (i.e., long-term future goals and career goals) and a $31 \%$ decline in relational distress (e.g., friendship patterns, sexual orientation/behavior, group loyalties). The comparison group, however, had a $21 \%$ increase in the number of individuals who reported relationship-oriented distress as their biggest stressor, and a slight decrease of $3 \%$ who reported more future-oriented distressors. It appears that participation in the CLP is associated with a change in focus toward more future-oriented concerns (i.e., long term goals and career concerns), whereas the normative alternative high school experience, as observed by the comparison group, results in increased concern regarding relationship issues. Taken alone, these findings provide no definitive answers as to whether one group's change is necessarily more suggestive of positive development than the others. Changes in the relative proportions of either group could be the result of individuals having effectively resolved their main distressor from pretest, only to attend to a new one at posttest. While it remains unclear exactly what these change results mean in an absolute sense, these findings do strongly suggest that generally, students' number one domain of identity distress is subject to change over a relatively short time span (approximately 10 weeks). 


\section{Exploratory Research Aim 4}

The fourth research aim was to evaluate personal expressiveness as a potential mediator of future possible selves. At the time of this study, concurrent research within the CLP had yet to produce findings with respect to self-construction identity exploration processes in the full sample used to test Model 1 (Figure 3). As such, preliminary data for a sixty-six person subset of the original sample was used. This model failed to show intervention effect on future possible selves (efficacy test), but retained the significant intervention effect on PE seen in Model 1 (specificity test). The significant condition effect on PE is especially noteworthy, demonstrating that this effect is indeed robust, as it remains strong despite an under-powered analysis.

In light of these findings, no further analyses were conducted. No additional meaningful relationships were found, including those originally found in Model 1. Because previous significant relationships from Model 1 were no longer present in Model 2 likely due to the reduced sample size, the possibility of Type II error is likely. However, as global fit indices for Model 2 indicate that the hypothesized relationship between these factors is plausible, future research may seek to reevaluate this, or similar, model using a larger sample size.

\section{Conclusions}

A main contribution of this study was to provide empirical evidence that selftransformative identity development intervention strategies demonstrate effectiveness in promoting emotion-focused identity exploration in adolescent youth. Specifically, this study found that intervention strategy intent on promoting self-directed change resulted in higher levels of feelings of "fit" between intervention participants life goals/activities and 
who they understand themselves to be, in contrast to those in the comparison group who were found to have less "fit" with their life goals/activities. As the comparison group utilized in this study represents the normative experience of alternative high school participation in Miami-Dade County, FL, declines in PE over time, coupled with the noted shifts in reported main identity-distressors, raises the possibility that the normative experience for alternative high school students is one of increased distress coupled with decreased emotion-focused self-exploration. Still unknown is whether these comparison participants will ultimately fare better or worse along the life course relative to the intervention group.

As participation in the CLP intervention appears to serve as a protective factor against declines in emotion-focused identity exploration, future longitudinal research might evaluate if this "protection" is maintained over time and whether it serves to facilitate positive self-directed change into the future. Similarly, future research may evaluate whether the declines observed in the comparison group are an indicator of less positive identity development and whether emotion-focused exploration remains less than that of intervention participants. Answers to these questions could have broad impact with respect to interventions with adolescents.

In terms of the intervention framework of the alternative high schools themselves, should declines in emotion-focused identity exploration be associated with more negative, long-term outcomes, self-transformative identity development strategies may be implemented as part of the general curriculum for all students as a means of promoting continued long-term, positive change. This may have broader implications for the various types of alternative school interventions currently used throughout the country (see 
Raywid, 1994), as those that seek to promote positive behavior change in addition to academic development may find the addition of strategies like self-discovery helpful. Alternatively, should declines in emotion-focused identity exploration be associated with more positive, long-term outcomes, empirical attention can turn toward evaluating other factors that may be associated with positive identity development, such as cognitive selfconstruction processes to self-development. Future research may also seek to investigate intervention outcomes when feelings of personal expressiveness are specifically targeted by the CLP intervention. An intervention activity adapted from that used by Schwartz et al. (2005) has been developed for use with adolescents (Albrecht, 2005b; see Appendix B). This activity is intended to augment the self-directed CLP intervention approach, specifically facilitating identification of personal interests and strengths that may benefit from integration with personally expressive activities.

A second contribution made by this study was the discovery of an unexpected relationship between PE and ID. Contrary to expectation, a statistically significant relationship between PE and ID was found where scores for both factors increase concurrently. Previous research on ID has characterized this type of distress as potentially deleterious to the process of identity development, primarily because high levels of distress have been associated with increased internalizing and externalizing symptoms that, in turn, may complicate one's navigation of identity-relevant contexts (Hernandez et al., 2006). While this may be true for those experiencing severe levels of distress, the association between increases in feelings of personal expressiveness and increases identity distress (to moderate levels) may be an indication of positive change, as increases in feelings of personal expressiveness indicate increased self-exploration; specifically, as 
these individuals more actively engage in consideration of identity-relevant information and the task of answering their own subjectively important life questions, they become more aware of how their life activities "fit" with who they are. These new considerations bring with them increased choices and possibilities; so while potentially exciting and fruitful, these new choices and possibilities are also somewhat distressing, as they require continued thought and engagement. Indeed, these findings are in line with theory that suggests adolescence to be a time of heightened stress and relative discomfort, while remaining a time of positive personal growth (Arnett, 1999; Cummings et al., 2000; Erikson, 1968). Examining change over time with respect to the domains of distress reported as the most-distressing domain of life, members of the intervention group experienced an overall shift from more immediate relational concerns toward more personal, future-oriented concerns; the comparison condition experienced an opposite trend. As mentioned above, the intervention condition reported a $28 \%$ increase in futureoriented distress and a $31 \%$ decline in relational distress, whereas the comparison group reported an approximate $10 \%$ decline in reports of future-oriented distress and a $16 \%$ increase in relational distress. As need for peer group affiliation peaks during adolescence (Cicchetti, 1993; Silverman \& Treffers, 2001), adolescents have been found to spend almost one third of their time with their peers (Csikszentmihalyi \& Larson, 1984). While considerable, this figure does not take into account the abundance of time likely spent thinking of or communicating with peers. Therefore, as peer-oriented attention increases, an overall increase in relational difficulties as the number one identity distressor has the potential to dramatically increase the time spent under duress, and/or one's attentional focus on these difficulties. Considering the comparison group's overall PE score declines, 
this raises the question whether focus on relationship difficulties may preclude attentional focus on other self-relevant aspects of life, particularly identity exploration.

Also, drawing from psychosocial theory, increased relational distress may be associated with the degree to which these individuals adequately resolve the adolescent identity crisis (Erikson, 1968). For the comparison group, the shift toward increased relational problems and decrease in affective self-exploration suggests that these individuals may be faring worse than CLP intervention participants in terms of actively engaging in their own self-development. However, as mentioned above, these preliminary findings offer little definitive evidence to claim so, for several reasons. First, as cognitive self-exploration was not investigated, comparison group members may have utilized more cognitive-oriented exploration processes at the time of assessment. Second, until follow-up data becomes available, it is unclear if the short-term gains found in this study translate into long-term positive gains. Finally, as the exploratory analyses conducted in this study were inconclusive due to small sample size, it is also unclear whether intervention or comparison participants showed more positive changes in their future possible selves, one outcome measure of positive identity development. A third broader contribution of this study was to identify what appear to be age, gender, and ethnic differences in the experience of emotion-focused identity exploration. Of particular interest are older females who were found to experience declines in feelings of personal expressiveness, opposite to changes observed in most other subgroups. As age differences in adolescence may reflect variations in identity-related experiences (Cummings, Davies, \& Campbell, 2000) or periods of particular sensitivity to family distress, developmental tasks such as career decisions, individuation from family, or 
romantic relationships (Cicchetti, 1993; Davies et al., 2000), future research may seek to pinpoint factors behind these differential effects, as gender role behavior and expectations are often strongly defined by one's ethnicity (Schwartz \& Montgomery, 2002; Sorrel \& Montgomery, 2001; Cole, 1998), thus suggesting that identity exploration processes may differ, as well. This may be particularly so for ethnic non-majority individuals (Barón, 1991; Fisher et al., 2002; Fisher, Jackson, \& Villarruel, 1997; Javier, 1995; LaFromboise, Hardin, Coleman, \& Gerton, 1993; Lin \& Kelsey, 2000; Nevid \& Maria, 1999; Rumbaut, 1991; Spencer, Swanson, \& Cunningham, 1991).

\section{Study Limitations}

\section{Participant Attrition}

At the time of this study, concurrent research within the CLP has yet to produce data with respect to participant attrition, though it is known to be considerable. Though the alternative high schools from which the sample was drawn do not record their own attrition data (R. Brandell, personal communication, February 9, 2007), Miami-Dade County Public Schools (MDCPS) reports county-wide graduation rates of approximately $59 \%$ and an official drop-out rate of $4.5 \%$. On-time graduation rates are reported at $45.3 \%$ (Toppo, 2006). None of these figures account for students who are not officially withdrawn. Because little specific information is available regarding these students, it is possible that selection effects are potentially biasing results. Future research may begin to address this issue. 


\section{Sample Size}

The small sample utilized in the mediation analysis of Model 2 may have resulted in Type II error, where differences in the variables were unobserved. Future research may consider re-examining the model using a larger sample size.

Directions for Future Research

Though a number of potential avenues for future research have already been proposed, perhaps the most fruitful toward the development of a self-transformative model of identity development would be the inclusion of measures of cognitive selfconstruction identity exploration processes into the model (as illustrated in Figure 4). The observed differences in emotion-focused identity exploration offer the possibility that self-discovery and self-construction, both plausibly linked to self-directed identity development, may have times within the developmental period of adolescence of increased relative importance to one another for specific individuals. As suggested by Soenens et al. (2005), individuals are believed to move back and forth between cognitive and affective evaluation of life experiences on a micro-level, where immediate thoughts and feelings interplay to facilitate the creation of one's subjective experiences toward life events. The same may be true on a broader level, where developmental challenges in one's life may require varying degrees of cognitive and affective exploration. As an example, for older high school students faced with the prospect of leaving their schools with no secured means of support for the future, the search for work and/or means of selfsustenance may be of highest priority; this decision-making may require more solutionsfocused, rational evaluation of potential options. At this time, emotion-focused exploration may decrease, at least temporarily. Or, for individuals faced with choosing 
one life choice versus another, such as a potential college major area of study, the utilization of emotion-focused exploration may provide insight to choose the line of study that feels "right" for them. As mentioned previously, perhaps those considered the most successful are those who effectively use both strategies.

In terms of empirical investigation, the relationship between self-construction and self-discovery may be competitive. As described by Jaccard (in review), mediation effects of a particular variable may be masked by other variables that also mediate the targeted outcome, or the mediator itself. Such a scenario would lead to Type II errors, where mediation effects go unobserved, but are actually present. This is plausible, considering the hypothesized relationship between self-construction and self-discovery on the development of a sense of self as illustrated in Figure 1 and should be considered in future studies. Overall, the findings of this study provide preliminary support for the general model of self-transformative identity development outlined in Figure 1, further providing a template onto which other putative factors of identity development can be mapped (e.g., measures of self, cognitive identity exploration, internalizing/externalizing behaviors, etc.). 


\section{REFERENCES}

Albrecht, R. E. (2005a). An investigation of the effects of a school-based intervention on feelings of personal expressiveness in multi-problem youth. Unpublished Master's thesis. Florida International University, Miami.

Albrecht, R. E. (2005b). A positive identity intervention to enhance emotion-focused choice making in self and identity development. Unpublished qualifying paper. Florida International University, Miami.

Archer, S. L. (Ed.). (1994) Interventions for adolescent identity development. Thousand Oaks, CA: Sage.

Arnett, J. J. (1999) Adolescent storm and stress, reconsidered. American Psychologist, 54(5), 317-326.

Barón, A. (1991) in Multicultural issues in counseling: New approaches to diversity. Lee, C.C \& Richardson, B. (Eds.). American Association of Counseling: Alexandria, VA.

Baron, R. M., \& Kenny, D. A. (1986). The moderator-mediator variable distinction in social psychological research: Conceptual, strategic, and statistical considerations. Journal of Personality and Social Psychology, 51, 1173-1182.

Berzonsky, M. D. (1989). The self as a theorist: Individual differences in identity formation. International Journal of Personal Construct Psychology, 2(4), 363376.

Bollen, K., \& Long, S. (1993). Testing structural equation models. Newbury Park: Sage.

Berkowitz, M. W., \& Bier, M. C. (2004). Research-based character education. Annals of the American Academy of Political \& Social Science Special. Positive Development: Realizing the Potential of Youth, 591, 72-85.

Berman, A. M., Schwartz, S. J., Kurtines, W. M., \& Berman, S. L. (2001). The process of exploration in identity formation. The role of style and competence. Journal of Adolescence, 24, 513-528.

Berzonsky, M. D. (1992). Identity style and coping strategies. Journal of Personality, 60(4), 771-788.

Berzonsky, M. D., \& Kuk, L. (2000). Identity status, identity processing style, and the transition to university. Journal of Adolescent Research, 15, 81-95.

Berman, S. L., Montgomery, M. J., \& Kurtines, W. K. (2004). The development and validation of a measure of identity distress. Identity, 4(1), 1-8. 
Biddle, B. J., \& Marlin, M. M. (1987). Causality, conformation, credulity, and structural equation modeling. Child Development, 58, 4-17.

Brandstaeder, J., \& Lerner, R. M. (Eds.) (1999). Action and self-development: Theory and research through the life span. Thousand Oaks, CA: Sage.

Burger, J. (1989). Negative reactions to increases in perceived control. Journal of Personality Social Psychology, 56, 246-256.

Byrne, B. M. (2001). Structural equation modeling with AMOS: Basic concepts, applications, and programming. Mahwah, NJ: Laurence Erlbaum Associates, Inc.

Catalano, R. F., Berglund, M. L., J. A. M. Ryan, Lonczak, H., \& J. D. Hawkins (1999). Positive youth development in the United States: Research findings on evaluations of positive youth development programs. Washington, DC: U. S. Department of Health and Human Services.

Cicchetti, D. (1993). Fractures in the crystal: Developmental psychopathology and the emergence of the self. Developmental Review, 11, 271-287.

Clausen, J. A. (1998). Life Reviews and Life Stories. In Giele, J. Z., \& Elder, G. H. (1998), Methods of life course research: Qualitative and quantitative approaches (pp. 189-212). Thousand Oaks, CA: Sage.

Cole, J. B. (1998). Commonalities and differences. In Anderson, M.L. and Collins, P.H. (eds.). Race, Class, and Gender: An Anthology. (pp. 175-180). Wadsworth, Belmont, CA,

Commission on Positive Youth Development. (2005). Seligman, M. E. P., Berkowitz, M. W., Catalano, R. F., Damon, W., Eccles, J. S., Gillham, J. E., Moore, K. A., Johnston-Nicholson, H., Park, N., Penn, D. L., Peterson, C., Shih, M., Steen, T. A., Sternberg, R. J., Tierney, J. P., Weissberg, R. P., Zaff, J. F. (2005). The positive perspective on youth development. In Dwight L. Evans, Edna B. Foa, Raquel E. Gur, Herbert Hendin, Charles P. O’Brien, Martin E. P. Seligman, \& B. Timothy Walsh (Eds.) Treating and preventing adolescent mental health disorders: What we know and what we don't know. (pp. 498-527). New York: Oxford.

Côté, J. E. (1994). Adolescent storm and stress. Hillsdale, NJ: Lawrence Erlbaum.

Côté, J. E., \& Allahar, A. L. (1996). Generation on hold: Coming of age in the late twentieth century. New York: New York University Press.

Côté, J. E. (1997). An empirical test of the identity capital model. Journal of Adolescence, 20(5), 577-597. 
Csikszentmihalyi, M. (1990a). Flow: The psychology of optimal experience. New York: Basic Books.

Csikszentmihalyi, M. (1990b). The domain of creativity. Theories of Creativity. Runco, M. (Ed.), Newbury Park, CA.:Sage Publications, 190-212.

Csikszentmihalyi, M. (1998). The development of the person: An experiential perspective on the ontogenesis of psychological complexity. In Damon, W. \& Lerner, R.M. (Eds.), Handbook of child psychology, Vol 1: Theoretical models of human development. New York, NY: Wiley.

Csikszentmihalyi, M. \& Larson, R. (1984). Being adolescent. New York: Basic Books.

Cummings, E. M., Davies, P. T., \& Campbell, S.B. (2000). Developmental psychopathology and family process: Theory, research, and clinical implications. Guilford Press: New York.

Damon, W. (2004). What is positive youth development? Annals of the American Academy of Political \& Social Science. Special Positive Development: Realizing the Potential of Youth, 591, 13-24.

Damon, W., \& Gregory, A. (2003). Bringing in a new era in the field of youth development. In R. M.. Lerner \& P. L. Benson (Eds.), Developmental assets and asset-building communities: Implications for research, policy, and practice. (pp. 47-64). New York, NY, US: Kluwer Academic/Plenum Publishers.

Damon, W., Menon, J., \& Bronk, K. C. (2003). The development of purpose during adolescence. Applied Developmental Science, 7(3), 119-128.

Eccles, J. S. (1996). The power and difficulty of university-community collaboration. Journal of Research on Adolescence, 6, 81-86.

DeCarlo, A. (2005). Identity matters: A new intervention threshold for social work practitioners working with African-American adolescents. Child \& Adolescent Social Work Journal, 22(1), 35-55.

Deci, E. (1992). The relation of interest to the motivation of behavior: A selfdetermination theory perspective. In Renninger, K., Hidi, S., and Krapp, A. (eds), The Role of Interest in Learning and Development (pp. 43-70) Erlbaum, Hillsdale, NJ.

Duchnowski, A. J., Kutash, K., \& Friedman, R. M. (2002). Community-based interventions in a system of care and outcome framework. In B.J. Burns \& $\mathrm{K}$. Hoagwood (Eds.) Community treatment for youth: Evidence-based interventions for severe emotional and behavioral disorders (pp. 16-37). New York: Oxford. 
Dunkel, C. (2000) Possible selves as a mechanism for identity exploration. Journal of Adolescence, 23, 519-529.

Dunkel, C., \& Kerpelman, J. (2006) Temporal comparisons, identity, and motivation: The relation between past, present, and possible future selves. Possible Selves: Theory, Research, and Applications. Hauppage, NY: Nova Science Publishers.

Dunkel, C., Kelts, D., Coon, B. (2006) Possible selves as mechanisms of change in therapy. In Dunkel, C. (Ed); Kerpelman, J. (Ed). Possible Selves: Theory, Research and Applications. (pp. 187-204). Hauppauge, NY: Nova Science Publishers.

Dunne, A., Thompson, W., \& Leitch, R. (2000). Adolescent males' experience of the counseling process. Journal of Adolescence, 23(1), 79-93.

Durlak, J., \& Wells, A. M. (1998). Evaluation of indicated preventive intervention (secondary prevention) mental health programs for children and adolescents. American Journal of Community Psychology, 26(5), 775-802.

Dworkin, J.B., Reed, L., \& Hansen, D. (2003). Adolescents' accounts of growth experiences in youth activities. Journal of Youth and Adolescence, 32(1), 17-26.

Elder, G. H. (1998a). The life course and human development. In R. M. Lerner (Ed.), Handbook of child psychology, Vol 1: Theoretical models of human development. New York, NY: Wiley.

Elder, G. H. (1998b). The life course as developmental theory. Child Development, 69 (1), 1-12.

Enright, R., Ganiere, D., Buss, R., Lapsley, D. \& Olson, L. (1983) Promoting identity development in adolescents. Journal of Early Adolescence, 3, 247-255.

Epstein, S. (1991). Cognitive-experiential self-theory: Implications for developmental psychology. In M.R. Gunnar \& L.A. Sroufe (Eds.), Self-processes and development: The Minnesota symposia on child psychology vol. 23. (pp. 79-123). Hillsdale, NJ: Lawrence Erlbaum Associates, Inc.

Erikson, E. H. (1959). Identity and the life cycle. New York: Norton.

Erikson, E. H. (1968). Identity: Youth and crisis. New York: Norton.

Freer-Wreder, L. A., Cass-Lorente, C., Kurtines, W. M., Briones, E., Bussell, J. R., \& Berman, S. L. (2002). Promoting identity development in marginalized youth. Journal of Adolescent Research, 17, 168-187. 
Fisher, C. B. (1997). A relational perspective on ethics-in-science decision-making for research with vulnerable populations. IRB: A Review of Human Subjects Research, 19,1-4.

Fisher, C., Hoagwood, K., Boyce, C., Duster, T., Frank, D., Grisso, T., Levine, R., Macklin, R., Spencer, M.B., Takanishi, R., Trimble, J.E., \& Zayas, L.H.. (2002). Research Ethics for Mental Health Science Involving Ethnic Minority Children and Youths. American Psychologist, 57(12), 1024-1040.

Fisher, C.B., Jackson, J., \& Villarruel, F. (1997). The study of African-American and Latin American children and youth. In W. Damon (Series Ed.) \& R.M. Lerner (Vol. Ed.), Handbook of child psychology: Vol. 1 Theoretical models of human development $5^{\text {th }}$ ed. (pp. 1145-1207). New York: Wiley.

Ferrer-Wreder, L., Cass Lorente, C., Kurtines, W. M., Briones, E., Bussell, J., Berman, S. L., \& Arrufat, O. (2002). Promoting identity development in marginalized youth. Journal of Adolescent Research, 17, 168-187.

Garcia, A. J. (2005). New directions in research on positive youth development interventions. Unpublished qualifying paper manuscript. Florida International University, Miami.

Gillham, J., \& Reivich, K. (2004). Cultivating optimism in childhood and adolescence. Annals of the American Academy of Political \& Social Science. Special Positive Development: Realizing the Potential of Youth, 591, 146-163.

Greenberg, M. T., \& Kusche, C. A. (1998). Preventive interventions for school-age deaf children: The PATHS curriculum. Journal of Deaf Studies \& Deaf Education, $3(1), 49-63$.

Greenberg, L., Rice, L., \& Elliott, R. (1993) Facilitating emotional change: The moment by moment process. Guilford Press: New York.

Grotevant, H. (1987). Toward a process model of identity formation. Journal of Adolescent Research, 2, 203-222.

Hall, G. S. (1904). Adolescence: Its psychology and relation to physiology, anthropology, sociology, sex, crime, religion, and education. (Vols. I and II). Englewood Cliffs, NJ: Prentice Hall.

Hawkins, J. D., Catalano, R. F., Kosterman, R., Abbot, R., Hill, K. G. (1999). Preventing adolescent health-risk behaviors by strengthening protection during childhood. Archives of Pediatrics \& Adolescent Medicine, 153, 226-234.

Herman-Stahl, M. \& Peterson, A. C. (1996). The protective role of coping and social resources for depressive symptoms among young adolescents. Journal of Youth and Adolescence, 25, 733-753. 
Hernandez, L., Montgomery, M. J., \& Kurtines, W. K. (2006). Identity distress and adjustment problems in at-risk adolescents. Identity, 6(1), 27-33.

Holland, J. L. (1973). Making vocational choices: A theory of careers. Englewood Cliffs, NJ: Prentice-Hall.

Holland, J. L. (1985). The Self-Directed Search: A Guide to Educational and Vocational Planning. Odessa, FL: Psychological Assessment Resources, Inc.

Holland, J. L. (1992). Making vocational choices: A theory vocational personalities and work environments (2nd ed.). Odessa, FL: Psychological Assessment Resources, Inc.

Holland, J. L., \& Rayman, J. R. (1986). The Self-Directed Search. In W. B. Walsh, \& S. H. Osipow (Eds.), Advances in vocational psychology: Vol. 1. The assessment of interests (pp. 55-82) Hillsdale, NJ: Erlbaum.

Holmbeck, G.N., \& Shapera, W. (1999). Research methods with adolescents. In P.C. Kendall, J..N. Butcher, \& G.N. Holmbeck (Eds.), Handbook of research methods in clinical psychology $2^{\text {nd }}$ ed. (pp. 634-661). New York: Wiley.

Honaker, J. Joseph, A. S., King, G., Blackwell, M. (2006) Amelia II: A program for missing data. Harvard University.

Hunter, J. P., \& Csikszentmihalyi, M. (2003). The positive psychology of interested adolescents. Journal of Youth and Adolescence, 32(1), 27-55.

Jaccard, J., Guilamo-Ramos, V., \& Blanton, H. A. Functional zero approach to testing partial versus complete mediation. Manuscript under review.

Javier, R. A. (1995) Machismo/marianismo stereotypes and Hispanic culture. In. J. Nevid, S. Rathus, \& L. Fichner-Rathus, Human sexuality in a world of diversity, $2^{\text {nd }}$ ed. (pp. 174-175). Needham Heights, MA: Allyn \& Bacon, Inc.

Jensen, P., Hoagwood, K., \& Trickett, E. (1999). Ivory towers or earthen trenches? Community collaborations to foster "real world" research. Applied Developmental Science, 3(4), 206-212.

Josselson, R. (1994). The theory of identity development and the question of intervention: An introduction. In S. L. Archer, (Ed.), Interventions for adolescent identity development. (pp. 12-28). Thousand Oaks, CA: Sage.

Kortsch, G. (2003). The possible selves method in evaluating youth development intervention: The use of integrated qualitative/quantitative data analytic strategies (IQ-DAS). Unpublished . Florida International University, Miami. 
Kortsch, G. \& Kurtines, W. K. (2005). The possible selves questionnaire-qualitative extension (PSQ-QE): Relational data analysis. New Directions in Promoting Positive Youth Development. Unpublished manuscript.

Kortsch, G., Kurtines, W. K., \& Montgomery, M. J. (2007/in press). The reliability, validity, and utility of the possible selves questionnaire (PSQ) in the evaluation of the changing lives program (CLP). Journal of Adolescent Research.

Kurtines, W. M., Ferrer-Wreder, L., Berman, S. L., Lorente, C. C., Briones, E., Montgomery, M. J., Bussell, J., Arrufat, O., \& Swenson, S. K. (2007/in press). Outreach research and new directions in developmental theory: The Miami Youth Development Project (YDP). Journal of Adolescent Research.

Kurtines, W. K., Montgomery, M. J., Lewis Arango, L., \& Kortsch, G. (2004). Does Intervention Change Anything? New Directions in Promoting Positive Youth Development. European Journal of Developmental Psychology, 1(4), 383-397.

Kurtines, W. (2005). Chair, symposium on Promoting Positive Youth Development: Outreach Research and New Directions in Developmental Theory, Methods, and Research Paper. Presented at the Society for Research on Identity Formation, Miami, Florida, Feb, 2005.

LaFromboise, T., Hardin, L., Coleman, K., \& Gerton, J. (1993) Psychological impact of biculturalism: Evidence and theory. Psychological Bulletin, 114, 395-412.

Larson, R. W. (2000). Toward a psychology of positive youth development. American Psychologist, 55(1), 170-183.

Lerner, R. M., \& Busch-Rossnagel, N. A. (1981). Individuals as producers of their development: Conceptual and empirical bases. In R. M. Lerner \& M. A. BuschRossnagel (Eds.) Individuals as producers of their development: A life span perspective (pp. 1-36). New York: Academic Press.

Lerner, R. M., Fisher, C. B., \& Weinberg, R. A. (2000). Toward a science for and of the people: Promoting civil society through the application of developmental science. Child Development, 71, 11-20.

Lerner, R., Jacobs, F., \& Wertlieb, D. (2003). Handbook of Applied Developmental Science: promoting positive child, adolescent, and family development through research, policies, and programs. Sage Publications: Thousand Oaks, CA.

Lewis-Arango, L. (2003). The utility of an integrated qualitative/quantitative data analytic strategy (IQ-DAS) to evaluate interventions on positive qualitative change in the life course. Unpublished dissertation. Florida International University, Miami. 
Lewis-Arango, L., Kurtines, W.M., Montgomery, M.J., Ritchie, R. (2007/in press) The reliability, validity, and utility of the Life Course Interview (LCI) in the evaluation of the changing lives program. Journal of Adolescent Research.

Lin, S., \& Kelsey, J. L. (2000) Use of race and ethnicity in epidemiologic research: Concepts, methodological issues, and suggestions for research. Epidemiological Reviews, 22(2), 187-202.

Markstrom-Adams, C., Ascione, F., Braegger, D., \& Adams, G. (1993). The effect of two forms of perspective taking on ego identity formation in late adolescence. Journal of Adolescence, 16, 217-224.

Maslow, A. (1968). The farther reaches of human nature. New York: Penguin.

Markus, H. \& Nurius, P. (1986). Possible selves. American Psychologist, 41(9), 954969.

McWhirter, E.H. (1994). Counseling for empowerment. Alexandria, VA: American Counseling Association..

McWhirter, E.H. (1997). Empowerment, social activism, and counseling. Counseling and Human Development, 29, 1-14.

McWhirter, E.H. (1998). An empowerment model for counselor training. Canadian Journal of Counseling, 32(1), 12-26.

Montgomery, M. J., Kurtines, W. K., Ferrer-Wreder, L., Berman, S. L., Lorente, C. C., Briones, E., Silverman, W. K., and Eichas, K. R. (2007/in press). A Developmental Intervention Science (DIS) Approach to Promoting Youth Development: Theoretical, Methodological, and Meta-Theoretical Challenges. Journal of Adolescent Research.

Nakamura, J., \& Csikszentmihalyi, M. (2002). The concept of flow. In C. R. Snyder \& S. J. Lopez (Eds.), Handbook of positive psychology (pp. 89-105). Oxford: Oxford University Press.

Nevid, J. S., \& Maria, N. L. S.. (1999). Multicultural issues in qualitative research. Psychology and Marketing, 16(4), 305-325.

Obler, L. K., \& Fein, D. (1988). The exceptional brain: Neuropsychology of talent and special abilities. New York: Guilford Press.

Ollech, D. \& McCarthy, J. (1997). Impediments to identity formation in female adolescents. Psychoanalytic Psychology, 14, 65-80.

Oyserman, D. (1997). Collectivism, personal autonomy, wealth and cognitive competence. Contemporary Psychology, 42, 790-792. 
Oyserman, D., \& Fryberg, S. (2006). The possible selves of diverse adolescents: Content and function across gender, race, and national origin. In Dunkel, C., Kerpelman, J. (Eds.) Possible selves: Theory, research, and applications (pp. 17-39). Hauppauge, NY: Nova Science Publishers.

Oyserman, D., Kemmelmeier, M., Fryberg, S., Brosh, H., \& Hart-Johnson, T. (2003). Racial-ethnic self-schemas. Social Psychology Quarterly Special: Race, Racism, and Discrimination, 66(4), 333-347.

Oyserman, D., \& Markus, H. (1990a). Possible Selves and Delinquency. Journal of Personality and Social Psychology. 59(1), 112-125.

Oyserman, D., \& Markus, H. (1990b). Possible Selves in Balance: Implications for Delinquency. Journal of Social Issues, 46(2), 141-157.

Parr, G., Montgomery, M., \& Bell, C. (1998). Flow theory as a model for enhancing student resilience. Professional School Counseling, 1(5), 26-31.

Peterson-Lewis, S., \& Bratton, L. M. (2004). Perceptions of “Acting Black” among African-American teens: Implications of racial dramaturgy for academic and social achievement. Urban Review, 36(2), 81-100.

Peterson, N. \& Reid, A. (2003) Paths to psychosocial empowerment in an urban community: Sense of community and citizen participation in substance abuse prevention activities. Journal of Community Psychology, 31(1), 25-38.

Pittman, K. J. (2000). What youth need: Services, supports, and opportunities, the ingredients for youth. Paper presented at the White House Conference on Teenagers, Washington, D.C., May 2, 2000.

Portnoi, L., Guichard, J., \& Lallemand, N.. (2003) The effect of career interventions designed to increase self-knowledge on the self-concepts of adolescents. Journal of Vocational Behavior, 65, 484-497.

Rausch, J. R., Maxwell, S. E., \& Kelly, K. (2003) Analytical methods for questions pertaining to randomized pretest, posttest, follow-up design. Journal of Clinical Child and Adolescent Psychology, 32(2), 467-86.

Raywid, M.A. (1994). Alternative schools: The state of the art. Educational Leadership, 52(1), 26.

Rich, G.J. (2003). The positive psychology of youth and adolescence. Journal of Youth and Adolescence, 32(1), 1-3.

Roderick, M. (2003). What's happening to the boys? Early high school experiences and school outcomes among African-American male adolescents in Chicago. Urban Education. Special Issue: Educating African-American Males, 38(2), 538-607. 
Rounsaville, B. J., Carroll, K. M., \& Onken, L.S.. (2001). A stage model of behavioral therapies research: Getting started and moving on from stage I. Clinical Psychology: Science and Practice, 48, 133-142.

Rumbaut, R. (1991). The agony of exile: a study of migration and adaptation in Indochinese refugee adults and children. In F.L. Ahean, Jr., \& J.L. Athey (Eds.), Refugee Children: Theory, research, and services. Baltimore: Johns Hopkins University Press.

Schultheiss, D., \& Blustein, D. (1994) Contribution of family relationship factors to the identity formation process. Journal of Counseling Development, 73, 159-166.

Schmidt, J. A., \& Padilla, B. (2003). Self-esteem and family challenge: An investigation of their effects on achievement. Journal of Youth and Adolescence, 32(1), 37-46.

Schwartz, S. (2006). In search of mechanisms of change in identity development: Integrating the constructivist and discovery perspectives in identity. Identity, 2(4), 317-339.

Schwartz, S. J., Kurtines, W. K.,\& Montgomery, M. J. (2005). A comparison of two approaches for facilitating identity exploration processes in emerging adults: an exploratory study. Journal of Adolescent Research, 20(3), 309-345.

Schwartz, S., \& Montgomery, M. (2002). Similarities or differences in identity development? The impact of acculturation on gender and identity process and outcome. The Journal of Youth and Adolescence, 31(5), 359-372.

Scitovsky, T. (1976). The Joyless Economy. Oxford University Press. New York.

Seligman, M., \& Csikszentmihalyi, M. (2000). Positive psychology. American Psychologist, 55(1), 5-14.

Seligman, M., Steen, T., Park, N., \& Peterson, C. (2005) Positive psychology progress: Empirical validation inventions. American Psychologist. 60(5), 410-421.

Silverman, W., \& Treffers, P. (2001). Anxiety disorders in children and adolescents: Research, assessment, and intervention. Cambridge University Press: Cambridge.

Sherrod, L. R., \& Brim, Jr., O. G. (1986). Epilogue: Retrospective and prospective views of life-course research on human development. In A. Sorensen, F. E. Weinert, \& L. R. Sherrod (Eds.), Human development and the life course: Multidisciplinary perspectives (pp. 557-575). Hillsdale, NJ: Lawrence Erlbaum.

Silverman, W., \& Kurtines,W. M. (1999). A pragmatic perspective toward treating children with phobia and anxiety problems. In Russ, S. \& Ollendick, T. (Eds.) Handbook of Psychotherapies with Children and Families. Issues in Clinical Psychology (505-521). Dortrecht Netherlands: Kluwer Academic Publishers. 
Solomon, D., Battistich, V., Watson, M., Schaps, E., Lewis, C. (2000). A six-district study of educational change: Direct and mediated effects of the child development project. Social Psychology of Education, 4(1), 3-51.

Sorrell, G., \& Montgomery, J. (2001). Feminist perspectives on the relevance of Erikson's theory for contemporary identity development research. Identity, 1, 97128.

Soenens, B., Berzonsky, M., Vansteenkiste, W., Beyers, W., \& Goosens, L. (2005). Identity styles and causality orientations: In search of the motivational underpinnings of the identity exploration process. European Journal of Personality, 19, 427-442.

Sommers-Flanagan, J., \& Sommers-Flanagan, R. (1997). Tough kids cool counseling: user-friendly approaches with challenging youth. American Counseling Association: Alexandria, VA.

Spencer, M. B., \& Markstrom-Adams, C.. (1990) Identity among racial and ethnic minority children in America. Child Development, 61, 290-310.

Spencer, M. B., Swanson, D.P., \& Cunningham, M. (1991). Ethnicity, ethnic identity, and competence formation: Adolescent transition and cultural formation. Journal of Negro Education, 60, 366-387.

Steen, T. A., Kanchorek, L.V., \& Peterson, C. (2003). Character strengths among youth. Journal of Youth and Adolescence, 32(1), 5-16.

Strauss, A., \& Corbin, J. (1998). Basics of qualitative research. Thousand Oaks, CA: Sage.

Sue, D. W., Carter, R. T., Casas, J. M., Fouad, N. A., Ivey, A. E., Jensen, M. et al. (1998). Multicultural counseling competencies: Individual and organizational development. Thousand Oaks, CA: Sage.

Sue, D. W. \& Sue, D. (2003). Counseling the culturally diverse: Theory and practice. New York: Wiley \& Sons.

Swanson, D., Beale Spencer, M., Dell'Angelo, T., Harpalani, V., \& Spencer, T. (2002) Identity processes and the positive youth development of African-American: An explanatory framework. New Directions in Youth Development, 95, 73-99.

Swenson, S. (2004). Participation in a positive youth development program and multiproblem alternative high school students' transformative goals: An investigation of the theoretical and methodological utility and validity of the transformative goal attainment scale (TGAS). Unpublished dissertation. Florida International University, Miami. 
Tierney, J., \& Grossman, J. B. (2000). What works in promoting positive youth development: Mentoring (pp. 323-328). Washington, DC, US: Child Welfare League of America, Inc.

Toppo, G. (2006). Big city schools struggle with graduation rates. USA Today [Electronic version]. Retrieved February 9, 2007, from http://www.usatoday.com/news/education/2006-06-20-dropout-rates_x.htm.

Waterman, A. S. (1984). Discovery or creation? Journal of Early Adolescence, 329-341.

Waterman, A. S. (1990). Personal expressiveness: Philosophical and psychological foundations. Journal of Mind and Behavior, 11, 47-74.

Waterman, A. S. (1994). Ethical considerations in interventions for promoting identity development. In S. L. Archer, (Ed.), Interventions for adolescent identity development. (pp. 231-244). Thousand Oaks, CA: Sage.

Waterman, A. S. (1995). Eudaimonic theory: Self-realization and the collective good. In W. M. Kurtines \& J. L. Gewirtz (Eds.), Moral development: An introduction. (p. 255-278). Boston: Allyn \& Bacon.

Waterman, A. S. (1993). Finding something to do or someone to be: A eudaimonist perspective on identity formation. Discussions on Ego Identity. Kroger, L., ed. Lawrence Erlbaum Associates, Inc., 147-167.

Waterman, A. (2004). Finding someone to be: Studies on the role of intrinsic motivation in identity formation. Identity, 4(3), 209-228.

Waterman, A. (2006). When effort is enjoyed: Two studies of intrinsic motivation for personally salient activities. Motivation and Emotion, 29(3), 165-188.

Waterman, S., Schwartz, S., Goldbacher, E., Green, H., Miller, C., Philip, S. (2003). Predicting the subjective experience of intrinsic motivation: The roles of selfdetermination, the balance of challenges and skills, and self-realization values. Personality and Social Psychology Bulletin, 29, 10, 1-12.

West, C. L. (1993). Race Matters. Boston: Beacon Press.

Wilson, D. B., Gottfredson, D. C., \& Najaka, S. S. (2001). School-based prevention of problem behaviors: A meta-analysis. Journal of Quantitative Criminology, 17(3), 247-272.

Yalom, I. (1995). The theory and practice of group psychotherapy. New York: Basic Books. 
Zimmerman, M.A. (1995). Psychological Empowerment: Issues and illustrations. American Journal of Community Psychology, 23(5), 581-599.

Zuckerman, M. (1979) Sensation Seeking. Hillsdale, NJ.: Erlbaum. 


\section{APPENDICES}

Appendix A: Relational Data Analysis (RDA)

This appendix describes RDA, a unified framework for relational data analysis. Relational Data Analysis (RDA) is a multidimensional, multiphasic framework for unifying the use of data analytic strategies across both dimensions of analysis (quantitative/qualitative, causal/structural, etc.) and phases of analyses (conceptual, theoretical, and research analyses). In developing RDA, the goal was to begin to articulate a data analytic framework that draws on a methodological metatheoretical framework, the relational developmental metatheory (Overton, 1998, 2003), that provides an alternative to the split metatheory framework, namely, an embodied person-centered approaches to psychological inquiry that provides a framework that more closely approximates the relational metatheoretical methodological ideal of overcoming the splits that have historically characterized methodological metatheory (Overton, 1998, 2003). The goal in developing RDA was to articulate a practical, ready-at-hand data analytic framework that could be used to address complex and difficult developmental issues in real life "applied" settings as well as clinic and laboratory settings.

RDA was developed as part of an ongoing program of research that has as one of its goals the development of community-based positive youth development interventions for changing the lives of troubled (multi-problem) youth (Lerner et al. 2000). When applied in conjunction with this program, RDA was intended to provide a unified framework for the use of relational data analysis in the service of our intervention goals, namely, identifying patterns of qualitative life course change (i.e., structural and developmental or directional change in the patterns of individual participants' life course 
or pathway) of the multi-problem youth who participate in our programs. To this end, $\mathrm{RDA}$ is intended to approximate the relational ideal by providing a framework that makes available to the researcher an array of research methods and procedures that can be relationally employed, as needed, across the full range of the dimensional splits that have historically characterized developmental research domains (qualitative/quantitative, structural/causal, expressive-constitutive/instrumental-communicative), and that also makes it possible to easily and readily switch between poles of the splits (qualitative $\rightarrow$ quantitative $\rightarrow$ qualitative..., structural $\rightarrow$ causal $\rightarrow$ structural...etc.) based on findings/results obtained at any phase of analysis (conceptual, theoretical, research analysis) and at any level of analysis (theory and data).

The Relational Circle

Figure 1 depicts the RDA framework visually. As can be seen from Figure 1, in an effort to represent the analysis of developmental data (or any other type of data) relationally, this framework depicts the analysis of change in expressive and instrumental action in the form of a relational circle with the movement of the analyses being characterized as cyclical. The relational circle and the concept of cyclical movement through the circle provide a useful way for representing the unification of analytical issues that have often historically been portrayed as split (Overton, 1998). A closer examination of Figure 1 further reveals that the application of RDA is multiphasic, being comprised of three analytic phases (Conceptual, Theoretical, and Research Analyses). In this framework, depending upon her/his research goal, a developmental researcher may begin analysis at any of the three phases. The framework then provides a suggested direction of movement. 
The relational circle and the concept of cyclical movement through the circle provide a useful way for representing the unification of analytical issues that have often historically been portrayed as split, but they do not address the critical need for the development of highly refined and consensually agreed upon methodological procedures and practices for resolving conflicting validity claims and eliminating rival or competing hypotheses. As Overton (1998) notes, some progress has been made, but the need exists to have ready-at-hand data analytic strategies for conducting structural analysis that can be broadly applied in a wide range of settings with diverse types of data. Further examination of Figure 1, for example, reveals that the three phases of RDA (Conceptual, Theoretical, Research) can be applied to change in either type of data (ExpressiveConstitutive or Instrumental-Communicative) and that cyclical movement through the core cycle alternates between two basic levels of analysis (Theory and Data).

Figure 1 further depicts that for each of the three phases of analyses, the two parallel types of analyses: Qualitative (Structural, Pattern, Transformational) and Quantitative (Causal, Functional, Variational) may be conducted during each phase and how the use of a relational framework facilitates the process of switching back and forth between poles of the splits (qualitative $\rightarrow$ quantitative $\rightarrow$ qualitative... structural $\rightarrow$ causal $\rightarrow$ structural...etc.) based on findings/results obtained at any phase of analysis (conceptual, theoretical, research) and at any level of analysis (theory or data).

As can also be seen from Figure 1, consistent with its multiphasic unified analytic framework, the three analytic phases of the core cycle of RDA form a relational circle that is cyclical and reciprocal. This feature of RDA, the reciprocal and cyclical movement between conceptual, theoretical, and research analysis phases, insures that the relational 


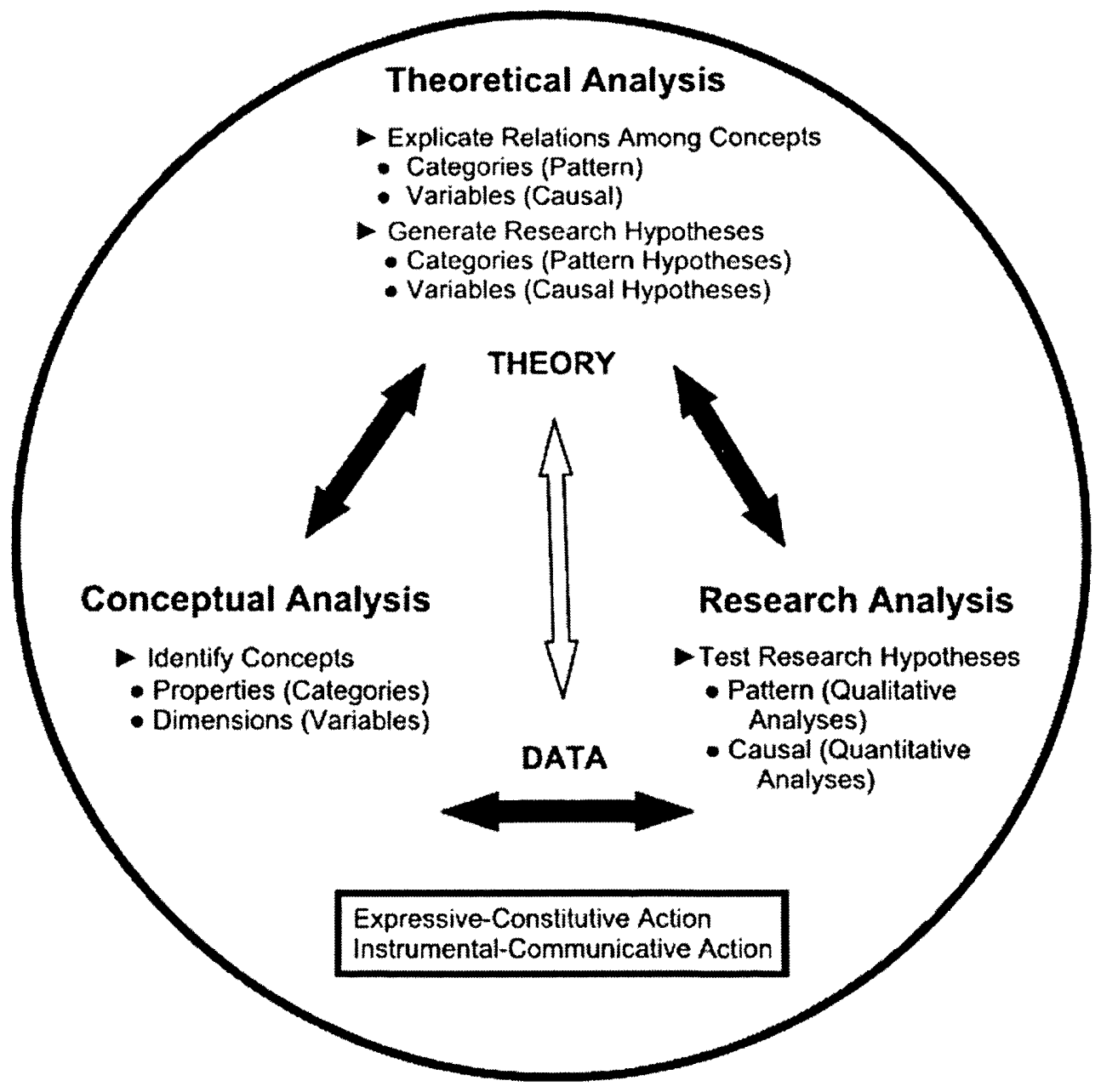

circle remains non-vicious because in the process of completing each full turn of the circle each cycle of the circle is open to diverse types of modification (i.e., conceptual, theoretical, or empirical) any (or all) of which are capable of transforming the movement of the next new cycle of the circle into a directional spiral.

Transforming the Relational Circle into a Directional Spiral

Figure 2 illustrates this process. As can be seen from Figure 2, after a researcher has collected data consistent with her/his research questions/goals and begins the conceptual analysis of the data, the forward movement through the core of RDA cycle 
generates the potential for transforming the relational circle into a directional spiral. During the conceptual analysis of the data, for example, findings/results from the conceptual analysis may result in the identification of new categories or variables and move the cycle forward to the next phase of analysis (theoretical analysis) or a lack of findings/results from the conceptual analysis (e.g., no relevant or meaningful new categories or variables) may result in the need to collect new data, with new findings/results from this data altering the direction of the circle and providing a new direction for the movement of the next cycle that spirals outward from the previous cycle. Forward and/or backward movement through each of the remaining phases of the cycle allows a similar possibility of altering the direction of the circle and transforming it into a spiral.

If the data analysis at the conceptual analysis phase, for example, results in the identification of new categories or variables and the cycle moves forward to the next phase of analysis (theoretical analysis), finding/results from the theoretical analysis of the data may result in the articulation of structural or causal hypotheses and move the cycle forward to the next phase of analysis (research analysis) or a lack of findings/results from the theoretical analysis (i.e., no relevant for meaningful theoretical or research hypotheses) may result in backward movement through the cycle (back to the conceptual analysis or even back to the collection new data) with new findings/results from this reanalysis or new data collection altering the direction of the cycle by providing a new direction for the movement of the next cycle that spirals outward from the previous cycle. Finally, if the theoretical analysis of the data result in the articulation of new structural or 
causal hypotheses and the cycle moves forward to the next phase (research analysis), negative findings/results from the hypotheses testing may result in bringing the

Figure 2: Transforming the Circle-Movement Through the Phases of the Core Cycle Enables Transforming the Relational Circle Into a Directional Spiral

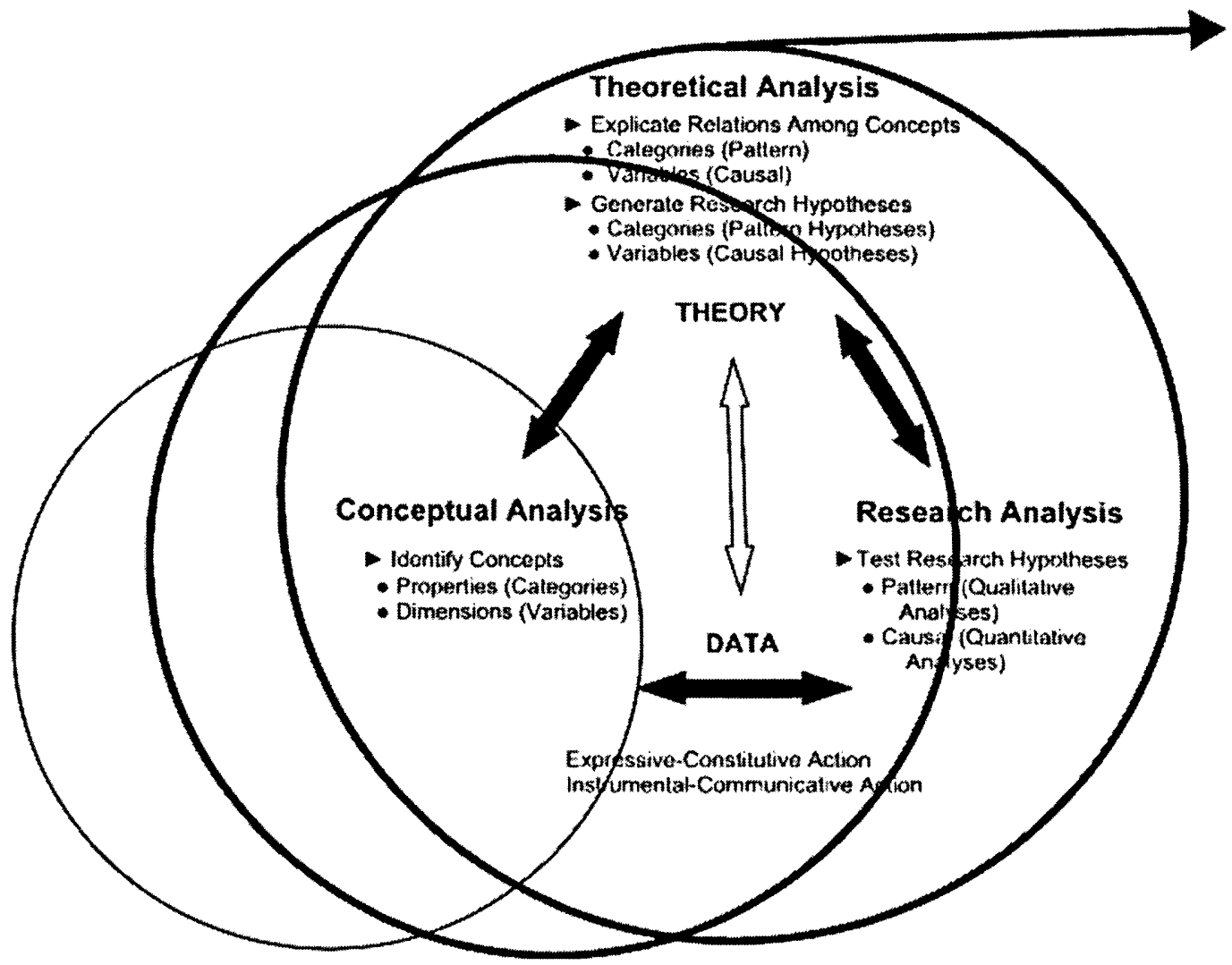

analytic cycle to an end if the negative result answers the research question(s) that initiated the cycle (or a return to earlier phases if they are not answered) and/or confirmatory findings/results from the hypotheses testing may bring the analytic cycle to an end if the confirmatory result answers the research question(s) that initiated the cycle or it may result in initiating another cycle of analysis by providing new directions for the movement of the next cycle in the spiral by raising new research question(s) thereby starting an entirely new core cycle. 
The methodological procedures and practices that we use as part of RDA for identifying and investigating structural/pattern hypotheses about expressive action draw primarily on grounded theory (Glaser \& Strauss, 1967; Strauss \& Corbin, 1998) as adapted for use in our research program. Within the qualitative research tradition, grounded theory is a well-established approach. Grounded theory (Strauss \& Corbin, 1998) has historically been identified with the sociological tradition in the human sciences. Emerging out of a field research tradition rather than a laboratory research tradition, grounded theory evolved in response to the need identify the subjective meaning and significance of research participants' open-ended responses (both between and within groups) in data sets collected using relatively unstructured non-experimental interview and field observational methods rather than causal or functional relations derived from behavioral observations in experimentally controlled laboratory or clinic settings.

RDA draws on grounded theory data analytic strategies (Strauss \& Corbin, 1998) for the qualitative methods that are used for each of RDA's three analytic phases. Specifically, Conceptual coding using open coding and the method of constant comparison for similarities and differences (as adapted for our research) are used in the Conceptual Analysis phase of RDA to identify all qualitatively different categories/variables in a particular data set. Theoretical coding using open coding and the method of constant comparison (as adapted for our research) are used in the Theoretical Analysis phase to identify the smallest set of theoretically meaningful (and qualitatively different) among the identified categories/variables. Theoretical sampling and theoretical saturation 
(as adapted for our research), complemented by quantitative methods, are used in the Research Analysis phase in evaluating qualitative research hypotheses.

Appendix B: Self-Transformation: Developing Personal Expressiveness

\section{Part I: Increasing Self-Awareness}

Rationale. As with many community-based interventions, because the CLP operates within a community with limited access to resources, and serves a population of multi-ethnic youth of both genders, the development and implementation of interventions designed to promote positive development for all participants is particularly useful. Because of this, the proposed intervention is designed to offer potential benefit to participants across both genders and all ethnicities. That is, this intervention is intended to be equally efficacious for all participants in promoting increased self-awareness and the ability to communicate with regard to their feelings and life goals.

As previously discussed, given the prevalence of adolescents who demonstrate difficulty in conceptualizing and discussing their thoughts and feelings, intervention with these individuals must begin by helping participants first identify their feelings. The identification of participants' feelings may ultimately be a first step toward facilitating participants' active development of their own sense of identity, given the specific developmental period spanned by the intervention (early to middle adolescence; ages 14 to 19), a critical stage that spans the time at which young people first begin to become aware of who they are, to the time at which young people begin to consolidate their sense of identity (Kurtines, 2005).

Specifically, part one of the intervention introduces participants to discussing themselves in terms of their strengths, unique potentials, abilities, and interests. For 
youth who may be particularly sensitive to disclosing information, focusing on the individuals' strengths as opposed to their problems and difficulties may encourage participation, as these individuals may find displaying their strengths to others as less threatening (Sommers-Flanagan \& Sommers-Flanagan, 1997). Furthermore, by discussing these matters in a group setting, all participants are likely to benefit by being able to see themselves in relation to their peers (Yalom, 1995). As the degree of sophistication participants will initially demonstrate in articulating their feelings and selfperceptions will vary, facilitators must take care to help participants to remain focused primarily on articulating their own interests and potentials (Greenberg, Rice, \& Elliott, 1993). By focusing on one's unique potentials and interests, participants will hopefully begin to be able to recognize, address, and articulate their own true feelings, while concurrently helping the focus of the group to shift toward personal introspection, as opposed to espousing the views of their respective peer groups.

Specifically, part one of the intervention uses a brief version of Holland's SelfDirected Search (SDS: Holland, 1985). Holland's SDS is a self-administered, self-scored, and self-interpreted vocational counseling tool (Holland \& Rayman, 1986) that defines individuals' interests and potential strengths according to six empirically derived types: realistic, investigative, artistic, social, enterprising and conventional (RIASEC). The more closely a person resembles a particular type, the more likely this person will exhibit the traits and behaviors of that type, with specific activities characterizing each type, or combination of types. This intervention, however, proposes using an abbreviated form of the SDS to begin to frame participants' discussion of themselves and their feelings and interests, as opposed to deriving specific potential occupations. Though the SDS has 
come to be primarily used in career counseling, research has demonstrated the utility of this type of tool to help adolescents improve overall self-awareness (Portnoi, Guichard, \& Lallemand, 2003). Such a tool may also serve to improve adolescents' ability to speak about identity-relevant issues by helping to frame such discussion and offer relevant vocabulary. In this case, the SDS is used primarily as a tool to focus participants attention to their personal interests and potentials, some of which they are likely to pinpoint for the first time in this exercise.

Because for many intervention participants, discussing and exploring the connection between "who one is" and "what one does" is in many ways new, a discussion framed by the six types of interest may help lead to greater exploration and expansion of the possible activities these individuals consider for their futures. In fact, preliminary research using the self-directed search as a tool to enhance self-knowledge shows promise in helping adolescents structure how they see themselves, in part by helping to frame the discussion of who they are and who they are not, based on their personal qualities (Portnoi, Guichard, \& Lallemand, 2003).

Implementation. The intervention begins with the facilitator giving a brief introduction of the exercise, explaining that participants are to complete an exercise that can help to clarify one's general interests. The facilitator hands out the SDS, and explains how to complete and score the form. After the activity is completed, the group facilitator introduces the general meaning of the six interest types to the group, and by asking openended questions, helps students explore the meaning and significance of these types, as they relate to them. After participants have had a short time to process the meaning of their interest types for themselves, participants will be asked to share their interest 
profiles with the group. The facilitator may ask participants to expand on their responses, perhaps asking what some have learned about their interests, or how this information may be valuable to them. The facilitator will conclude the activity by asking students how their interest profiles may be useful in making life choices.

\section{Part II: Enhancing Emotion-Focused Decision Making}

Rationale. The second part of the intervention will proceed likely on the following session, once participants have taken part in the SDS activity. Presumably, by this time, individuals are able to articulate to some degree their general interests. The second part of the intervention consists of increasing intervention participants' emotionfocused decision-making regarding identity-relevant choices by encouraging participants to recognize and increasingly incorporate personally expressive activities into their daily life and future goals. As developed by Schwartz et al. (2005), and consistent with the theoretical approach of the CLP, the theoretical platform for the intervention strategies used is based on the notion of transformative pedagogy introduced by Freire (1970/1983) and refined for use in identity interventions by Ferrer-Wreder et al. (2002). Learning is facilitated through problem-posing, participatory learning, and transformative activities. Participatory learning experiences provide a context for individuals' participation in a conjoint learning process in which they, with the guidance of a group facilitator, provide the answers to their own questions and to those posed by other group members. One notable change from the Schwartz et al. (2005) intervention is the substitution of the concept of flow for feelings of personal expressiveness. As previously mentioned, flow and personal are closely related levels of self-discovery (Schwartz, 2001; Waterman, 1990). However, as the experience of flow is produced by a balance between the 
challenges posed by an activity or goal and the skills that one brings to it and results in an unconstrained sense of time and intense engagement in the activity or pursuit of the goal (Csikszentmihalyi, 1990a; 1990b; Waterman et al., 2003), the concept of flow may not be a useful concept with adolescents, as most of the adolescents of the CLP have had limited to no experience in actually performing many of the activities they ultimately wish to participate in. Because of this, many of these individuals may have yet to experience a state of flow. As such, using flow as a central focus in an intervention with adolescents may serve only to exclude a number of individuals who have yet to experience such a state. These adolescents do however have a greater likelihood of being able to speak of their general feelings regarding specific activities and whether those activities seem to "fit" or be expressive of what they understand their interests and potentials to be.

Implementation. Part two of intervention begins with each participant writing down up to the three life goals that he or she has previously rated on the assessment battery at pretest. Each member will briefly discuss these goals with the group. For each goal, participants will follow a series of steps with help from fellow group members.

First, the goal is broken down into component activities (e.g., going to law school = reading, studying, memorizing). Second, the participant is asked to associate each component activity with feelings and feeling words (e.g., angry, stressed, fearful), with the group facilitator using the experiential focusing technique outlined by Greenberg, Rice, and Elliott (1993) to inform how the intervention proceeds.

Using Greenberg et al.'s techniques, participants may be encouraged by their group facilitator to engage in the intervention in four basic dimensions, through the use of open-ended questions intended to address and clarify participants' inner experience 
toward the subject at hand. The degree to which these dimensions are addressed depends on the ability of the group to articulate their inner experiences, thoughts, and feelings, and it is left to the discretion of the group facilitator to decide the degree to which participants may require assistance in addressing these their feelings, as defined by these dimensions. The dimensions include: Attending/Awareness; Experiential Search, Active Expression; and Interpersonal Learning.

The Attending/Awareness dimension refers to making contact with basic sensory information about oneself when coming into contact with specific information, in this case the activities and interests already discussed in the intervention. As participants begin to focus on their present states, participants are encouraged to gain awareness of their immediate responses to the subject matter, including bodily and emotional changes that may result from discussing the feelings associated with their responses in steps one and two. Clients might describe getting a "charge" when discussing something they enjoy, or awareness of muscle tightness at the discussion of something more aversive. This dimension is addressed as a first step toward greater self-awareness of participants' initial reaction to specific identity-relevant information.

The Experiential Search dimension refers to symbolizing participants' possibly complex inner experiences with some type of descriptive label that seems to characterize the inner experience of this new information; most importantly, individuals are asked to begin to voice their inner experiences as a first step toward increased self-reflection even if they feel unable to fully capture their experience into words. By actively seeking to label their particular inner experience and vocalize it to the group, participants can take initial steps toward clarifying and identifying their own specific emotional responses to 
the subject at hand. Responses may include statements like "I'm feeling as if I'm about to fall," or "it's like I'm at a stop sign and don't know which way to turn." Such symbolic language helps participants gain a better understanding of their inner experiences. This process also serves to move the group process forward, as each participants' responses may help other participants to articulate their own inner experiences.

The Active Expression dimension refers to the active expression of an individual's perceived needs with regard to their future life goals. That is, participants are asked to discuss their future goals and related activities in terms of their emotional needs. This dimension seeks to enhance participants' self-reflection and ability to articulate their feelings, but also to complete the relationship between one's life activities and the feelings associated with them. By actively expressing this connection, the relationship between these activities and personal feelings is available for further reflection. Furthermore, participants begin to move beyond symbolizing their experiences. By focusing on their personal needs, participants take the first steps toward actively approaching decision-making that is informed by their own feelings.

As the final dimension, participants are asked to receive the emotional and cognitive information that may have resulted from the previous steps and participate in interpersonal learning. This occurs through active discussion and sharing of participants' experience, as well as exploration of potential ramifications or consequences of the feelings and experiences discussed. Particularly, at this time, participants are believed to benefit from the overall therapeutic attitude provided by the group facilitator that expresses value for individuals who make decisions for themselves. While the group facilitator helps participants to formulate ideas and make connections between life 
activities and their own feelings, participants are believed to gain a sense of trust for their own experiences, as well as learn to better see themselves in relation to other group members, as a means of learning more about themselves. Furthermore, these groupexperiences may provide participants with new self-understanding that may help to disconfirm previous beliefs, as well as expand upon helpful and insightful ideas the participants may be able to articulate. These four dimensions can be addressed by the group as the group facilitator asks open-ended questions that address each dimension. Once the facilitator feels as if the group has demonstrated thoughtful attention to these four dimensions, the intervention may proceed to the next step.

The third step of the intervention consists of the group facilitator introducing the concept of personal expressiveness, using Waterman et al.'s (2003) six descriptors, listed previously. Fourth, participants are instructed to create a list of activities that he or she associates with feelings of personal expressiveness, and the facilitator writes these down (perhaps on a blackboard) so as to share the list with the group, as the participants enumerate them. Finally, the group is asked to construct goals based on these personally expressive activities and to creatively integrate these personally expressive goals into the participants' existing personal goals. The participant is then asked to reflect on these integrated goals with the group.

Consistent with Schwartz et al. (2005), participants are also encouraged to engage in transformative activities outside of the group based on the ideas and solutions proposed in session. Engaging in self-directed transformative activities allows young people to practice solving the problems, making the choices, reaching the goals, and 
playing the roles that have an impact on the quality of their lives. Future group discussion is encouraged, as participants will hopefully, over time, begin to incorporate these ideas into their lives. 
1991-1995

1995-1998

1998

1998-2000

2002-2006

2002-2003

2002-2005

2003-2007

2005-2006

2005-2007
B.A., English

Allegheny College

Meadville, Pennsylvania

Corporate Sales Coordinator

Borders, Inc.

Miami, Florida

New Teacher of the Year

Miami Palmetto High School

Language Arts Instructor

Palmetto Senior High School

Miami, Florida

Group Facilitator

Youth Development Project

Miami, Florida

Therapist, Practicum

State Inpatient Psychiatric Unit

Jackson Hospital

Miami, Florida

M.S., Psychology

Florida International University

Miami, Florida

Teaching Assistant

Florida International University

Miami, Florida

Therapist, Practicum

Counseling and Psychological Services

Florida International University

Miami, Florida

Doctoral Candidate, Psychology

Florida International University

Miami, Florida 


\section{PUBLICATIONS AND PRESENTATIONS}

Garcia, A., Albrecht, R., Ritchie, R., Varela, A., Wang, R., Eichas, K., \& Kurtines, W. (2006, March). Promoting positive youth development: Using within regression analysis to estimate group process growth curves as mediators of intervention change in multi-problem youth. Poster presented at the Society for Research on Identity Formation, San Francisco, CA.

Kurtines, W. M., Ferrer-Wreder, L., Berman, S. L., Cass Lorente, C., Briones, E., Montgomery, M. J., Albrecht, R., Garcia A., \& Arrufat, O. (in press). Promoting positive youth development: Outreach research and new directions in developmental theory--the Miami Youth Development Project (YDP), Journal of Adolescent Research.

Kurtines, W. M., Montgomery, M. J., Eichas, K., Ritchie, R., Garcia, A. J., Albrecht, R. E., Berman, S., Ferrer-Wreder, L., \& Cass Lorente, C. (In press). Promoting positive identity development in troubled youth: A developmental Intervention science approach, Journal of Adolescent Research.

Kurtines, W. M., Montgomery, M. J., \& Lewis Arango, L., Kortsch, G., Albrecht, R., Garcia A. (in press). Relational Data Analysis (RDA), Journal of Adolescent Research.

Lisa Lewis Arango, Arlen Garcia, Richard Albrecht, Lynn Hernandez, William Kurtines (April, 2002). Using Life Stories in Evaluating Youth Development Interventions: An Investigation of the Utility of the Life Course Interview (LCI). Paper presented at the biennial meeting of the Society for Research on Identity for Formation, New Orleans, LA.

Silvia Sullivan, Arlen Garcia, Richard Albrecht, William Kurtines (2003, May). Normative Life Course Change. Poster presented at the Society for Research in Identity Formation's biennial convention, Vancouver, BC, Canada.

William Kurtines, Sara Swenson, Silvia Sullivan, Arlen Garcia, Richard Albrecht, Michael Mira, Summer Brooke Gomez (2003, May). Responses to the Postmodern Challenge: Youth Identities Revisited. Paper presented as part of a symposium on The Postmodernist Critique of the Developmental Approach to Identity: How Much Is Fact and How Much Is Fiction? at the Society for Research on Identity Formation, Vancouver, Canada, May, 2003. 